Provided by the author(s) and University of Galway in accordance with publisher policies. Please cite the published version when available.

\begin{tabular}{|c|c|}
\hline Title & $\begin{array}{l}\text { Metallacarboranes and their interactions: theoretical insights } \\
\text { and their applicability }\end{array}$ \\
\hline Author(s) & $\begin{array}{l}\text { Farràs, Pau; Juárez-Pérez, Emilio J.; Lepšík, Martin; Luque, } \\
\text { Rafael; Núñez, Rosario; Teixidor, Francesc }\end{array}$ \\
\hline $\begin{array}{c}\text { Publication } \\
\text { Date }\end{array}$ & $2012-02-14$ \\
\hline $\begin{array}{l}\text { Publication } \\
\text { Information }\end{array}$ & $\begin{array}{l}\text { Farras, Pau, Juarez-Perez, Emilio J., Lepsik, Martin, Luque, } \\
\text { Rafael, Nunez, Rosario, \& Teixidor, Francesc. (2012). } \\
\text { Metallacarboranes and their interactions: theoretical insights } \\
\text { and their applicability. Chemical Society Reviews, 41(9), 3445- } \\
\text { 3463. doi: } 10.1039 / \text { C2CS15338F }\end{array}$ \\
\hline Publisher & Royal Society of Chemistry \\
\hline $\begin{array}{l}\text { Link to } \\
\text { publisher's } \\
\text { version }\end{array}$ & http:/dx.doi.org/10.1039/C2CS15338F \\
\hline Item record & http://hdl.handle.net/10379/5954 \\
\hline DOI & http://dx.doi.org/10.1039/C2CS15338F \\
\hline
\end{tabular}

Some rights reserved. For more information, please see the item record link above. 


\section{Metallacarboranes and their Interactions: Theoretical}

\section{Insights and their Applicability ${ }^{\dagger}$}

Pau Farràs, ${ }^{\mathrm{a}}{ }^{\ddagger}$ Emilio J. Juárez-Pérez, ${ }^{\mathrm{b} \ddagger}$ Martin Lepš́k, ${ }^{\mathrm{c}}$ Rafael Luque, ${ }^{\mathrm{d}}$ Rosario Núñez ${ }^{\mathrm{e}}$ and Francesc Teixidor ${ }^{\mathrm{e}}$

${ }^{\text {a }}$ Institute of Chemical Research of Catalonia (ICIQ), Av. Països Catalans 16, E-43007 Tarragona (Spain). Tel: + 34977 920200. E-mail: pfarras@ iciq.es

${ }^{\mathrm{b}}$ Instituto Nacional del Carbón (INCAR-CSIC). C/ Francisco Pintado Fe 26, E-33011 Oviedo (Spain). Tel: +34 985 119090. Email: emilio@incar.csic.es

${ }^{c}$ Institute of Organic Chemistry and Biochemistry, v.v.i. Academy of Sciences of the Czech Republic. Flemingovo nám. 2. 16610 Praha 6. (Czech Republic)

d Departamento de Química Orgánica, Universidad de Córdoba. Campus de Rabanales. Edificio Marie Curie (C-3) Ctra Nnal IV, Km 396, E-14014 Córdoba (Spain)

e Institut de Ciència de Materials de Barcelona (ICMAB-CSIC), Campus de la U.A.B., E-08193 Bellaterra (Spain)

$\dagger$ This review is dedicated to the memory of Prof. William N. Lipscomb, the 1976 Nobel Prize winner for illuminating the structure and bonding of boranes, who died on April $14^{\text {th }}, 2011$.

$\$$ P.F and E.J.J-P contributed for the same level of authorship credit 


\begin{abstract}
This tutorial review will deal with the study of metallacarboranes and their interactions with other molecules from a theoretical point of view. We devote this contribution to experimental chemists to guide them through calculations that some years ago were reserved to theoretical specialists. The widespread availability of fast computers enables nowadays studies of complex compounds, such as metallacarboranes, from different perspectives, e.g. simulation of NMR, infrared or raman spectra and calculation of other properties such as atomic charges or inter-/intramolecular interactions. The insights gained on the basis of theoretical calculations are crucial for either finding novel or improving the existing applications of metallacarboranes. For example, in the case of enzyme inhibitors, the interactions of the metallacarboranes with the surrounding protein and how the interaction affects the efficiency is a difficult problem to study experimentally. However, the use of theoretical tools provides a detailed understanding of the physico-chemical basis of the interactions and thus offers a chance to control the overall process.
\end{abstract}




\section{1.- Introduction: metallacarboranes.}

Metallacarbaboranes (or metallacarboranes) are a class of inorganic polyhedral clusters containing carbon, boron, hydrogen, and metal atoms in various combinations. A typical metallacarborane is a sandwich of two $\left[\mathrm{C}_{2} \mathrm{~B}_{9} \mathrm{H}_{11}\right]^{2-}$ (dicarbollide) clusters with a metal ion in the center (Figure 1.a). The $\left[\mathrm{C}_{2} \mathrm{~B}_{9} \mathrm{H}_{11}\right]^{2-}$ behaves as a $\eta^{5}$ ligand and is considered isolobal to the cyclopentadienyl $\left(\mathrm{Cp}^{-}\right)$ligand, as e.g. in ferrocene. Therefore, some similarities can be drawn between the $\mathrm{Co}$ (III) metallacarborane and the $\mathrm{Co}(\mathrm{II}) \pi$ complex $\mathrm{CoCp}_{2}$ cobaltocene, although it has been observed that the behavior is rather different, especially regarding their stability. ${ }^{1}$

Metallacarboranes are becoming subject of a growing interest to the broad chemical community for their unique combination of features and properties, such as the rigidity of the cages and their relative rotary motion, hydrophobicity, and chemical and thermal stability due to delocalized charge. The inclusion of carbon atoms in the boron framework causes a differential reactivity of the cluster with either acidic (carbonbound) or hydridic (boron-bound) hydrogen atoms. Moreover, replacement of a metal by another one further increases the variability, influencing, e.g. the charge or redox properties. Altogether, a broad range of interactions can be formed between metallacarboranes and their neighboring molecules.

It has to be mentioned that two different types of compounds can be found, named endo- and exo- metallacarboranes. This review will deal only with endometallacarboranes, where the metal center is sandwiched by the carborane clusters. Conversely, in exo-metallacarboranes a metal fragment is linked to the periphery of the carborane skeleton, typically through B-H $\cdots \mathrm{M}$ interactions. Moreover, the known and 
characterized metallacarboranes vary in size from 4 to 14 vertices in a single polyhedral framework, although the majority of them contain $\mathrm{C}_{2} \mathrm{~B}_{3}, \mathrm{C}_{2} \mathrm{~B}_{4}$, or $\mathrm{C}_{2} \mathrm{~B}_{9}$ ligands able to function as 6-electron donors to the metal center (Figure 1, drawing of the most wellknown types of metallacarboranes). As this work focuses on theoretical calculations, for a detailed review on experimental work done on metallacarboranes refer to Grimes' review. $^{2}$

From a theoretical point of view, metallacarboranes have not been extensively studied. This might be due to the rather large size of the cluster, taking into account that most of the work done on metallacarboranes has been focused on the commocobaltabisdicarbollide $\left[3,3^{\prime}-\mathrm{Co}-\left(1,2-\mathrm{C}_{2} \mathrm{~B}_{9} \mathrm{H}_{11}\right)_{2}\right]^{-}$, (Figure 1.a), having at least 45 atoms (23 non-hydrogen) in the structure. Additional complications arise if a transition metal heavier than Co is present in the skeleton (relativity effects become more important), not to mention the hundreds of described derivatives arising by the substitution of one or more hydrogen atoms. Furthermore, many different isomers might exist within the same compound, e.g. for $\left[3,3^{\prime}-\mathrm{Co}-\left(1,2-\mathrm{C}_{2} \mathrm{~B}_{9} \mathrm{H}_{11}\right)_{2}\right]^{-}$a total of 48 isomers are topologically possible although only two of them are currently known. Altogether, during the last two decades some calculations have been done on metallacarboranes but most of them based only on geometry optimization or NMR spectrum prediction.

The availability of faster computers and a wider use of computational chemistry for organometallic compounds have produced a significant increase in reports combining experimental and theoretical techniques on metallacarboranes in the last decade. Most important is that theoretical results were not only able to qualitatively describe various phenomena but also, by using more demanding computational methods, quantify some properties that up to that time could only be obtained experimentally or that were 
unknown. $^{3}$ The situation became crucial when some of the applications of metallacarboranes required a detailed understanding of their behavior, such as their surfactant properties in radionuclide extraction or non-covalent interactions with proteins in studies of their medicinal applications. These tasks enforced the use of special methodologies to study the interactions between metallacarboranes and their surroundings.

In the following text, we would like to summarize the theoretical methodologies used so far, the information that can be gained using them and a selection of some applications to metallacarboranes where calculations proved to be vital for a detailed understanding of these molecular systems.

\section{2.- Methods and software used in metallacarborane computations.}

It should be emphasized that the aim of this review is to be a helpful guide to (mostly experimental) chemists, physicists and biologists who are interested in interpreting their experimental data on metallacarborane properties with the help of theoretical calculations. On the other hand, skilled computational chemists interested in these compounds could find this review useful as an updated comprehensive summary of the calculations on metallacarboranes performed until now and they can safely skip this section.

There are several books covering the main topics of this review, such as transition metal clusters, ${ }^{3}$ and more specific on borane based compounds, ${ }^{4}$ to name a few examples. As mentioned earlier, metallacarboranes are a huge family of compounds composed of a few to several dozens of B, C, H and metal atoms. Some of their properties, such as charge delocalization over the cage or charge transfer to the metal ion, warrant the use 
of quantum chemical (QM) computational methods. The best compromise between speed and accuracy on these electronically complex compounds is represented by the density functional theory (DFT) approach, which has been widely used in this area. Alternatively, the use of a potentially more accurate and CPU time and disc-space more demanding Møller-Plesset MP2 method did not yield much better results, and thus, DFT is preferred. The most commonly used DFT functionals are B3LYP and BP86 coupled with Gaussian-type basis sets of double- or triple- $\zeta$ quality. For details, it is recommended to read the literature on DFT calculations and to check out the specific references in this review.

A short note on the semiempirical quantum mechanical (SQM) methods is given here owing to their relative simplicity which enabled their use in the early days of theoretical research on metallacarboranes. Currently, corrected versions of modern semiempirical quantum mechanical methods, such as PM6-DH2 or SCC-DF-TB-D, are available featuring the highest level of accuracy at a marginal computational cost and having a potential to be used in metallacarborane calculations.

Heavy elements like metals are problematic atoms, even in the QM calculations. Usually the calculation is designed to be done with effective core potentials instead of core orbitals producing large time savings and with little loss of information. Another problem working with metals are the relativistic effects, which must be taken into account if we are working with elements of the fifth and sixth periods.

Quantum chemistry calculations can nowadays be routinely run using either proprietary software packages like ADF, Gaussian or Turbomole, or academic freeware programs, such as Gamess-US, ORCA or Firefly. 
For other types of applications, force-field based molecular mechanics (MM) and dynamics (MD) methods can be used to study static properties and dynamic behavior of metallacarboranes. However, such an approach must be viewed with caution because of the inherent limitations of the MM methods, e.g. the lack of an explicit description of electronic effects, which underline some of the metallacarborane properties and the need of ad hoc parametrization. Nevertheless, the use of MD proved to be useful for sampling possible configurations of (rigid) metallacarboranes, e.g. while studying their surfactant behavior in solution (see Section 4c).

The next sections contain a set of reviewed papers where only a brief description of the computational technique is given. The researcher should check the original work for details of the computational method. We apologize for any papers that could be omitted here for space reasons. The numerous acronyms used are explained in Table 1.

\section{3.- Properties simulated using calculations.}

3.a) Geometries, metal-ligand coordination modes and interpretation of molecular orbitals.

In practically all the articles reviewed below, the experimental work produced structures of all or part of the metallacarboranes under study by using X-ray diffraction, gas-phase electron diffraction or NMR. The addition of theoretical calculations served as a valuable complement to this work for, i) obtaining structural data for compounds that could not be obtained experimentally, ii) discussing reaction mechanisms quantitatively 
using postulated intermediates, iii) studying the strength of a chemical bond beyond the distance obtained experimentally and iv) showing the disposition of the molecular orbitals on the compound structure. DFT is one of the tools that the experimental chemist specialized in metallacarborane chemistry has very closely at hand and this review is intended to be a starting point for assistance from theoretical chemistry. A review about computational methods on transition metal clusters highlights its importance for the understanding of structural cluster chemistry and how it supports each other with the classical electron counting rules. ${ }^{3}$

General considerations to bear in mind in this section are that the calculations on the geometries of metallacarboranes agree fairly well with the experimental ones to within $0.01 \AA$ or less for bond length differences, although bonds involving metal atoms show slightly larger discrepancies. NMR theoretical calculations are another extraordinary tool for structure elucidation and an entire section in this review is dedicated to it (see section 3.b). Interpretation of the $3 \mathrm{D}$ electronic probability contour plots of the HOMO and LUMO or related molecular orbitals help to understand many chemical features of these compounds.

Although the study by Morokuma et al. in $a b$ initio theoretical calculations using Hartree-Fock (HF) and MP2 methods focused only on metallaboranes, ${ }^{5}$ it is relevant as it represented a pioneering work where the different problems associated with the theoretical calculations on metallaboranes were shown. All the relevant conclusions could be extrapolated to metallacarboranes. i) the bond distances in metallaboranes with Ir, Co and Fe were more accurately predicted with MP2 than with HF methods and ii) the metal-boron distances were less accurate than others. The relative stability calculated for two isomers, where the metal is located in the apical or basal position 
(Figure 1.b), was found to depend on the method used, HF or MP2. Interestingly, the two bridging hydrogen atoms in the Co based metallaboranes interact with the metal ignoring the boron atoms. This result was not consistent with the findings of X-ray studies and the authors attributed it to possible differences between the molecular structures in the solid, liquid or gas-phase state without external interactions, the last two being closer to the physical reality of calculation.

Geometry calculations on metallacarborane compounds will be reviewed below in this section with the aim to give the reader an overview of the type of information that can be obtained. Full details of how the calculations were carried out are omitted here due to the limited space of this review but can be found in the cited references. In many cases, only the most recent reference has been included, nevertheless it is strongly recommended to explore the earlier papers published by each research group. This section is organized into three subsections, metallacarboranes with subicosahedral, icosahedral and supraicosahedral carborane clusters. In some cases, these subsections have been divided by generic family of compounds. 


\section{3.a.1) Metallacarboranes with subicosahedral carborane clusters.}

The first studies were done by Maguire et al. ${ }^{6}$ using the simple MNDO-type of semiempirical calculations on closo-stannacarborane $\left(\mathrm{C}_{2} \mathrm{~B}_{3}\right)$ derivatives. It was found that the Sn atom slippage toward the unique boron side of the $\mathrm{C}_{2} \mathrm{~B}_{3}$ ring is influenced by ligands such as bipyridine. This slippage is the result of various overlap interactions between the Sn and carborane orbitals. Molecular orbital energy calculations showed contributions from the Sn and those MO's localized on carbons and borons of the $\mathrm{C}_{2} \mathrm{~B}_{3}$ ring.

Timofeeva et al. ${ }^{7}$ applied MM methods with force field parameters obtained from HF/6$31 \mathrm{G}^{*}$ ab initio calculations within pentagonal bipyramid metallacarborane model compounds $\left(\mathrm{M}-\mathrm{C}_{2} \mathrm{~B}_{4} \mathrm{H}_{6}, \mathrm{M}=\mathrm{Mg}, \mathrm{SiH}_{2}\right)$. This compound set was later expanded to include carborane isomers of $\mathrm{C}_{2} \mathrm{~B}_{5} \mathrm{H}_{7}$. The theoretical data obtained were used to predict qualitatively the conformational preferences of sandwich metal complexes of $\mathrm{Si}, \mathrm{Ge}, \mathrm{Sn}$ and $\mathrm{Pb}$.

Ezhova et al. ${ }^{8}$ reported a work applying DFT-B3LYP methods to a set of pentagonal bipyramid metallacarborane derivatives (1-ML-R- $\mathrm{C}_{2} \mathrm{~B}_{4} \mathrm{H}_{5}, \mathrm{M}=\mathrm{Na}, \mathrm{Li} ; \mathrm{L}=$ solvent; $\mathrm{R}=$ silanes). These compounds have a capping s-block metal in the apical position above the open $\mathrm{C}_{2} \mathrm{~B}_{3}$ face. It was found that the carbon-apart isomer has a greater relative stability than carbon-adjacent isomer by $15-25 \mathrm{kcal} / \mathrm{mol}$ depending on the substituent (Figure 1.c).

Du et al. ${ }^{9}$ optimized the structure of an eleven-vertex manganese-monocarbaborane dianion radical $\left(\left[1,1,1-(\mathrm{CO})_{3}-2-\mathrm{Ph}-\text { closo-1,2- } \mathrm{MnCB}_{9} \mathrm{H}_{9}\right]^{\mathrm{n}-}, \mathrm{n}=1,2\right)$ using unrestricted B3LYP theory. The SOMO probability 3D contour plot showed an anti-bonding character between the $\mathrm{Mn}$ atom and the carborane cage, and their unpaired electron was 
distributed over both the carborane cage and the metal center, Figure 2. The authors proposed that such delocalization contributes to the unusual stability of this radical.

De Biani et al. ${ }^{10}$ studied experimentally the electronic interactions and metal-metal communication in a wide range of double and triple-deckers of cobaltacarboranes and ferracarboranes (Figure 1.d). Important features of the redox behaviour can be related with the results of the MO's calculations within the model compounds. In general, it was found that frontier orbitals had contributions from the $\sigma$ and $\pi$ orbitals of the $\left[\mathrm{C}_{2} \mathrm{~B}_{4} \mathrm{H}_{6}\right]^{2-}$ and $d_{x y}$ and $d_{y z}$ orbitals from the metal fragment, and the strong overlap between the carborane ligand HOMO and the metal $d$ orbitals resulted in high delocalization.

De Montigny et al. ${ }^{11}$ found experimentally a transition-metal-facilitated process in an iridacarborane. DFT studies described the binding mode of the promoter to the substrate and a study of the MO's in model compounds showed the strong and weak interactions involved in the process.

Nafady et al. ${ }^{12}$ studied an analogue compound for cymantrene where the Cp was substituted by tricarbadecaboranyl ligand (Figure 1.e). Experimentally, the derivative showed outstanding lower reduction potential meaning that tricarbadecaboranyl was highly electron-accepting ligand. Restricted and unrestricted DFT calculations of neutral, monoanion or dianion model compounds supported the experimental findings. The SOMO in the monoanion compound showed their relevant mediation in its electron-transfer-induced hapticity change. The optimized geometries of the three complexes agreed very well with the available X-ray structures. Voltammetry and IR experiments had been very well corroborated by the calculations. 
DFT calculations showed the bonding properties of anions $\left[\mathrm{CpCo}-\left(1,3-\mathrm{C}_{3} \mathrm{~B}_{2} \mathrm{H}_{5}\right)\right]^{-}$and $\mathrm{Cp}^{-}$toward transition metals. ${ }^{13}$ The Energy Decomposition Analysis (EDA) method used by the authors was a useful tool to examine the nature of metal-ligand bonding in these triple-decker complexes. Bonding interactions in both cases were found to be $c a$. $40 \%$ covalent and $60 \%$ electrostatic in nature. Furthermore, the $\pi$ donation in the covalent bonding was important but $\sigma$ donation was much greater in the former case compared to $\mathrm{Cp}^{-}$.

\section{3.a.2) Metallacarboranes with icosahedral carborane clusters.}

Webster et al. ${ }^{14}$ studied the "de novo" design of ligands to stabilize $\operatorname{Ir}(\mathrm{V})$ species, which are an important intermediate in the $\mathrm{C}-\mathrm{H}$ bond activation. The authors considered the dianion $\left[\eta^{5}-7,8-\mathrm{C}_{2} \mathrm{~B}_{9} \mathrm{H}_{11}\right]^{2-}$ as a promising candidate because it presents good donor properties (Figure 1.f). However, DFT studies showed that an oxidative addition reaction of $\mathrm{CH}_{4}$ over the metal centre did not produce an $\operatorname{Ir}(\mathrm{V})$ stable complex. It was concluded that the carborane-based ligands studied were unable to stabilize $\operatorname{Ir}(\mathrm{V})$ because the charge density was delocalized around the carborane cage and thus was not available for the metal. Fox et al. ${ }^{15}$ carried out DFT studies of the $\sigma$-donor/ $\pi$-acceptor properties of $\left[\mathrm{SnCB}_{10} \mathrm{H}_{11}\right]^{-},\left[\mathrm{SnB}_{11} \mathrm{H}_{11}\right]^{2-}$, 3-Sn-1,2-C $\mathrm{C}_{2} \mathrm{~B}_{9} \mathrm{H}_{11}$, and related $\mathrm{SnC}_{2} \mathrm{~B}_{\mathrm{n}} \mathrm{H}_{\mathrm{n}+2}$ compounds. $\left[\mathrm{SnB}_{11} \mathrm{H}_{11}\right]^{2-}$ was shown to be a very strong donor, whereas the dicarbon cluster 3-Sn-1,2- $\mathrm{C}_{2} \mathrm{~B}_{9} \mathrm{H}_{11}$ was a poor $\sigma$-donor but good Lewis acid. [ $\left.\mathrm{SnCB}_{10} \mathrm{H}_{11}\right]^{-}$had intermediate $\sigma$-donor $/ \pi$-acceptor properties between those two. This work described the properties, shapes and energies of frontier orbitals and their capabilities for ligand binding (Figure 3). 
McIntosh et al. ${ }^{16}$ isolated C-atom isomerised species of $\left(\eta-\mathrm{C}_{7} \mathrm{H}_{7}\right) \mathrm{MoPh}_{2} \mathrm{C}_{2} \mathrm{~B}_{9} \mathrm{H}_{9}$. DFT calculations showed that these Mo based metallacarboranes showed a room temperature isomerization route similar to that observed for the high-temperature isomerisation of the $\mathrm{C}_{\mathrm{x}} \mathrm{B}_{\mathrm{x}}$ carborane from 1,2 to 1,7 .

Tri- and tetra-carbollides (carborane species with three- and four-carbon vertices)

Perekalin et al. ${ }^{17}$ used DFT methods to study ferra-, cobalta- and ruthenatricarbollide polyhedral rearrangements. Relative stabilities of carbon isomers, estimation of the strength of the metal-tricarbollide bonding and comparison with metallocenes was carried out.

Kiani et al. ${ }^{18}$ performed a systematic theoretical DFT study on icosahedral heteroboranes incorporating transition metals from groups 8,9 and 10 in diamagnetic 12-vertex closo-cyclopentadienylmetallaheteroborane clusters with several $\mathrm{C}$ and/or $\mathrm{P}$ heteroatoms. They found rules of additive nature by using structural energy increments that allowed to predict the most stable isomers.

DFT B3LYP calculations have been used $^{19}$ to optimize the structures of magnesacarboranes. The reaction of the carbon-apart isomer of tetracarba-nidododecaborane with the s-block metal $(\mathrm{Mg})$ produced metallacarboranes with a variety of cage structures. The $\mathrm{Mg}$ atom was strongly bonded to two carbons of the $\mathrm{C}_{3} \mathrm{~B}_{4}$ open face ring and it can be considered as $\eta^{2}$-bonded to the cage.

\section{Constrained geometries}

DFT calculations were done on the structure of the constrained-geometry of complexes based on dicarbollide ligand (see Figure 1.f for an example of a constrained geometry). 
For example, using $\mathrm{Al}$ as metal centre, as in $\left[\left(\eta^{5}-\mathrm{R}\left(\mathrm{C}_{2} \mathrm{~B}_{9} \mathrm{H}_{9}\right) \mathrm{CH}_{2}\left(\eta^{1}-\mathrm{NH}_{2}\right)\right] \mathrm{Al}(\mathrm{Me})\right.$, the $\pi$-bonding interaction between the dicarbollide and $\mathrm{Al}$ is stronger than between $\mathrm{Cp}$ and Al. ${ }^{20}$ The dicarbollide ligand stabilizes the $\eta^{5}: \eta^{1}$-bonding mode better than the $\mathrm{Cp}$ analogue compound and according to the authors both the $\sigma$-contribution from the amine and the $\pi$-electronic contribution from the dicarbollide create and ideal bonding environment for the formation of novel constrained-geometry complexes. The formation of $\pi, \sigma$-bonding is energetically more stable than $\sigma, \sigma$-bonding as well as the methylenespaced amino function is more favorable than the ethylene-tethered ligand system.

Sandwich complexes (complexes formed by two separated ligands $\pi$-bonded to the same metal centre)

Hawthorne et al. ${ }^{21}$ carried out DFT calculations for the Ni(III) and Ni(IV) unsubstituted sandwich complexes of bisdicarbollide ligands, [3,3'-Ni-(1,2- $\left.\left.\mathrm{C}_{2} \mathrm{~B}_{9} \mathrm{H}_{11}\right)_{2}\right]^{-}$and 3,3'-Ni$\left(1,2-\mathrm{C}_{2} \mathrm{~B}_{9} \mathrm{H}_{11}\right)_{2}$, respectively. These calculations supported the view that paramagnetic transoid $d^{7} \mathrm{Ni}(\mathrm{III})$ and diamagnetic cisoid $d^{6} \mathrm{Ni}(\mathrm{IV})$ compounds could be exchangeable by redox and photochemical reactions. Geometry optimizations showed that the minimum energy correspondeds to a transoid configuration of the $\mathrm{Ni}(\mathrm{III})$ and a cisoid configuration for the Ni(IV) bisdicarbollide species, thus oxidation state decided the most stable isomer. It was found that the HOMO of the $\mathrm{Ni}(\mathrm{IV})$ bisdicarbollide species was connecting the two dicarbollide ligands while the strongly antibonding LUMO has a nodal plane through the nickel atom.

Bühl et al. have done the most extensive study on dicarbollide sandwich complexes of $d$-block metals by using mainly DFT-BP86 calculations. The first work deals with the optimization of the structures of the cobaltabisdicarbollide ion [3,3'-Co-(1,2- 
$\left.\left.\mathrm{C}_{2} \mathrm{~B}_{9} \mathrm{H}_{11}\right)_{2}\right]^{-}$in selected carbon isomers and rotamers. ${ }^{22}$ Energy rotational profiles calculations show that there are three staggered minima (transoid, gauche and cisoid) separated by three eclipsed transition states rotamers. Another work expanded the study with complexes of bisdicarbollide ligands with $\mathrm{d}^{6}$ metals $\mathrm{Fe}(\mathrm{II}), \mathrm{Ru}(\mathrm{II}), \mathrm{Co}(\mathrm{III}), \mathrm{Rh}(\mathrm{III})$, $\mathrm{Ni}(\mathrm{IV})$ and $\mathrm{Pd}(\mathrm{IV})$, as well as selected mixed- and half-sandwich complexes. ${ }^{23}$ Also from Bühl et al. ${ }^{24}$ are the computational studies on protonated iron bisdicarbollide, $\left[3,3^{\prime}-\mathrm{Fe}-\left(1,2-\mathrm{C}_{2} \mathrm{~B}_{9} \mathrm{H}_{11}\right)_{2} \mathrm{H}\right]^{-}$. They found that the protonated species has the minimum energy rotamer in the cisoid conformation in contrast with the unprotonated form that favors transoid. The authors claim that rotary motion could be induced by exchanging basic or acidic media in a similar manner as the rotary motions of the $\mathrm{Ni}(\mathrm{III}) / \mathrm{Ni}(\mathrm{IV})$ pair were induced by redox/photochemical process. ${ }^{21}$

Núñez et al. ${ }^{25}$ used ZINDO/1 semiempirical methods to study the conformations of neutral and positively charged bisdicarbollide sandwich complexes prepared by chargecompensated nido-[10-SMe $\left.-7,8-\mathrm{C}_{2} \mathrm{~B}_{9} \mathrm{H}_{10}\right]^{-}$with different transition metals such as $\mathrm{Co}(\mathrm{II}), \mathrm{Co}(\mathrm{III}), \mathrm{Ni}(\mathrm{II}), \mathrm{Ru}(\mathrm{II})$ and $\mathrm{Fe}(\mathrm{II})$. The $\mathrm{X}$-ray diffraction studies were in very good agreement with the global energy minimum calculated by this method.

Juárez-Pérez et al. ${ }^{26}$ used DFT-B3LYP calculations to study the conformational behavior and relative energies of several C-mono- and C-disubstituted derivatives of [3,3'-Co- $\left.\left(1,2-\mathrm{C}_{2} \mathrm{~B}_{9} \mathrm{H}_{11}\right)_{2}\right]^{-}$with organosilane groups showing a good agreement with $\mathrm{X}$ ray diffraction structural data.

Farràs et al. ${ }^{27}$ employed DFT to elucidate the reaction mechanism of multiple B-C bonds in a Heck-type reaction on cobaltabisdicarbollide. It was hypothesized at which point the second alkene compound was attached to the cluster and that this was possible through an unprecedented B-H activation. The same authors made use of theoretical 
calculations to study a new set of complexes named metallacyclophanes. ${ }^{28}$ Interestingly, it was observed that the electron lone pair on phosphorus was able to communicate between the donor and acceptor moieties on the compound. Conversely, when the electron lone pair was used to form a bond with the chalcogen atom, this communication was shut down.

\section{Mixed pyrrolyl/dicarbollyl sandwich complexes}

The first studies within mixed pyrrolyl/dicarbollide complexes were carried out in 2001 combining $\mathrm{HF} a b$ initio and ZINDO/1 semiempirical methods. This early study examined the $\mathrm{C}_{\mathrm{c}} \cdots \mathrm{C}_{\mathrm{c}}$ bond distance plasticity and the authors interpreted that such dependency was related to the partially filled LUMO antibonding orbital partially filled that decreased the bond order. ${ }^{29}$ Viñas et al. also used ZINDO/1 semiempirical methods to study the conformations of mixed sandwhich dicarbollide/pyrrolyl complexes. ${ }^{30}$

\section{Mixed cyclopentadienyl/dicarbollyl vs dicarbollyl sandwich Co complexes}

Perekalin et al. ${ }^{31}$ studied the thermodynamic stability of the nine possible isomers of 12 vertex cobaltacarborane $\mathrm{CpCoC}_{2} \mathrm{~B}_{9} \mathrm{H}_{11}$ using the DFT method. They found that the stability of such compounds increased with increasing distance between the carbon atoms in the carborane moiety and it was virtually independent of the metal-carbon distance. The relative stabilities increased from ortho- and meta- to para-. These results are similar with findings from Bühl et al. ${ }^{22}$ In both cases, there was a clear separation between carbon adjacent and carbon separated isomers, the latter being more stable. The trend within these two groups is slightly altered if the accompanying ligand is a $\mathrm{Cp}$ or 
the corresponding symmetric dicarbollide ligand, see Figure 4. It is also observed that the energy difference is more pronounced for the $\left[\mathrm{Co}-\left(\mathrm{C}_{2} \mathrm{~B}_{9} \mathrm{H}_{11}\right)_{2}\right]^{-}$complexes.

\section{3.a.3) Metallacarboranes with supraicosahedral carborane clusters.}

\section{3-vertex heteroborane ligands}

At least three geometries of 13-vertex clusters based on carborane are experimentally known: docosahedron, henicosahedron and ditrapezoidal icosahedron (Figure 1.g). ${ }^{32}$ The most studied 13-vertex metallacarboranes adopted the docosahedron geometry in their ground state but the henicosahedron geometry can be found as intermediates or transition states. It was calculated by $\mathrm{DFT}^{33}$ that the docosahedron is preferred over the henicosahedron for $\left[\mathrm{B}_{13} \mathrm{H}_{13}\right]^{2-}(0.9 \mathrm{kcal} / \mathrm{mol})$ but for $1,2-\mathrm{C}_{2} \mathrm{~B}_{11} \mathrm{H}_{13}$, the reverse trend was shown $(1.8 \mathrm{kcal} / \mathrm{mol})$.

Welch's group $^{34}$ has several works including theoretical studies of 13-vertex supraicosahedral metallacarboranes $4-\mathrm{MC}_{2} \mathrm{~B}_{10}$. Metal atoms studied were $\mathrm{Sn}, \mathrm{Ru}, \mathrm{Pd}$, $\mathrm{Pt}, \mathrm{Fe}$ and Co. See for example a recent DFT structural study for 13-vertex naphthalene ferracarboranes $\mathrm{FeC}_{2} \mathrm{~B}_{10} \mathrm{H}_{12}$, where the possible $\mathrm{C}$ isomers of the docosahedral 4,1, $\mathrm{X}$ $\mathrm{MC}_{2} \mathrm{~B}_{10}$ family are the 4,1,2-, 4,1,5-, 4,1,6-, 4,1,8-, 4,1,10-, 4,1,11- and 4,1,12-. Usually, the metal atom occupies vertex 4 , one of the positions of the highest connectivity, and one carbon atom occupies vertex 1 , a position with 4 connectivities. The isomer 4,1,12has the carbon atoms in para disposition and it is usually the most stable isomer. A theoretical fluxional process on the 13-vertex cage has shown the double diamondsquare rearrangement involving a $\mathrm{C}_{\mathrm{s}}$ transition state. Geometry optimizations showed well reproduced structures but discrepancies between the observed and computed M-B or M-C distances were found. The authors stated that these structural differences lay on 
a very shallow potential energy surface and a henicosahedral transition state geometry could be located above the usual ground-state docosahedral structure.

Recently, the mechanism of an aromatic C-C bond cleavage by a 13 -vertex adduct of ruthenacarborane has been investigated using DFT calculations. ${ }^{35}$ The intermediate structure was found and the energy profile of the reaction pathway calculated.

\section{4 vertex cluster ligands}

King et al. ${ }^{32}$ calculated relative energy stabilities of 14 -vertex clusters using the Ge atom as vertex instead of B-H, C-H or metals. Wade-Mingos rules suggest the bicapped hexagonal antiprism for $\mathrm{Ge}_{14}{ }^{2-}$ similar to that found experimentally in metallacarboranes. However, this DFT study predicted a symmetrical $\mathrm{O}_{\mathrm{h}}$ omnicapped cube to be the most stable structure for the $\mathrm{Ge}_{14}{ }^{2-}$ cluster by at least $43 \mathrm{kcal} / \mathrm{mol}$. Metal atoms have a more flexible bonding mode; in fact, they prefer the higher connectivity positions in metallacarboranes, whereas $\mathrm{B}$ and especially $\mathrm{C}$ atoms prefer low connectivity positions.

An early DFT study on a 14-vertex bimetallic closo-ruthenacarborane was done by Bühl et al. ${ }^{23}$ The position of the $\mathrm{C}$ atoms in the carborane framework can be established from geometry optimizations of the most probable isomers and NMR experimental data. By comparing bond distances between theoretical and experimental structures it is difficult to determine unambiguously the structural isomer, but it can be used to discard the carbon adjacent isomer. NMR calculations show that the correct isomer has the carbon atoms in the farthest apart positions (Figure 1.h). 


\section{3.b) Simulation of NMR, IR and RAMAN Spectra}

NMR is probably the most widely used spectroscopic technique in modern chemical research. Its high sensitivity and easiness of application makes it a valuable experimental tool for structure determination. However, theoretical predictions of NMR spectra significantly lagged after the experimental practice. The major problem slowing down the theoretical progress has been simply that it is more difficult to model the interactions of a wave function with a magnetic field than it is with an electric field. Nevertheless, great progress has been made during the last decades and the calculation of chemical shifts is becoming more and more routine.

Theoretical NMR calculations have proven the most useful tool to determine the geometry of metallacarboranes when no X-ray structure is available. It was first demonstrated on unsubstituted boranes that very accurate NMR predictions could be obtained using $a b$ initio methods. ${ }^{36}$ Later on, and with the aid of more powerful computers, this approach could also be applied to metallaboranes ${ }^{5}$ and metallacarboranes. $^{22}$

As mentioned in the introduction, the elements present in a metallacarborane molecule are $\mathrm{B}, \mathrm{C}, \mathrm{H}$, and a metal, at least. Among these, boron is a perfect candidate for NMR spectroscopy. The ${ }^{11} \mathrm{~B}$ isotope has a nuclear spin of $3 / 2$, a $80.42 \%$ abundance, and a good NMR sensitivity. Therefore, the calculations of ${ }^{11} \mathrm{~B}$ NMR chemical shifts $-\delta\left({ }^{11} \mathrm{~B}\right)$ - represent a powerful tool for experimental boron chemists and, in fact, it is one of the preferred means of characterization of boron-based compounds. The combination of calculated and experimental $\delta\left({ }^{11} \mathrm{~B}\right)$ values has become important in structural studies of such compounds. The methodology being used in the last years corresponds to geometry optimizations at ab initio levels and calculations of chemical shifts using the 
IGLO-SCF, GIAO-SCF, GIAO-DFT or GIAO-MP2 procedures. The accuracy of these methods on metallacarboranes depends on the nature of the metal; for more demanding transition-metal atoms a higher than MP2 level of calculations would be needed in order to decrease the error. The average error for calculated $\delta\left({ }^{11} \mathrm{~B}\right)$ values is $c a .5 \mathrm{ppm} .{ }^{22}$ Moreover, when heavier atoms are incorporated in the cluster, relativistic effects named spin-orbit (SO) coupling have to be included in the calculation, even for the calculation of ${ }^{11} \mathrm{~B}$ NMR chemical shifts. These calculations are done with the ZORA approximation method, which includes scalar and SO corrections to the NMR calculations. ${ }^{23}$

NMR spectroscopy simulation can be applied to calculate the chemical shifts of the remaining atoms of the cluster. Then, ${ }^{1} \mathrm{H}$ and ${ }^{13} \mathrm{C}$ NMR values can also be calculated using the same methodology although the accuracy for $\delta\left({ }^{1} \mathrm{H}\right)$ values is yet to be demonstrated. Moreover, the information gathered from the calculation of $\delta\left({ }^{13} \mathrm{C}\right)$ is limited because there is not a significant change of the values depending on the geometry of the compound. Finally, computed NMR values on metal centers have been almost unexplored in metallacarborane chemistry despite being a powerful tool to study their structures and reactivities. Metal centers are very sensitive to geometrical changes and thus, the study on their NMR chemical shift has been applied in a number of inorganic and organometallic compounds. So far, only two references have been found in the literature, one for ${ }^{57} \mathrm{Fe},{ }^{24}$ and the other for ${ }^{59} \mathrm{Co} .{ }^{22}$ However, ${ }^{57} \mathrm{Fe}$ has not proven useful due to its low receptivity, which would make the experimental test of predicted values very difficult. On the other hand, ${ }^{59} \mathrm{Co}$ is a relatively well-behaved metal for NMR spectroscopy and it can be observed in a variety of molecules including large biomolecules. Having a good methodology to calculate $\delta\left({ }^{59} \mathrm{Co}\right)$ values could be 
important as the chemical shifts cover a total range of about $20000 \mathrm{ppm}$ and, therefore, are very sensitive to small changes.

In general, density functional methods have produced the best results on the prediction of chemical shifts for metallacarboranes. It is well established that the hybrid B3LYP functional provides the best results in comparison to pure HF or other hybrid functionals with a higher HF exchange contribution. As for the basis set, qualitative analysis can be performed using LANL2DZ basis set although better results are obtained with simple double or triple- $\zeta$ basis sets, such as $6-31+\mathrm{G}^{*}$ or $6-311+\mathrm{G}^{*}$. It has also been demonstrated that inclusion of the solvent does not, in general, affect the chemical shifts in metallacarboranes, but causes a high computational cost. Figure 5 shows a comparison of calculated $\delta\left({ }^{11} \mathrm{~B}\right)$ using different DFT functionals for the cobaltabisdicarbollide anion.

Validation of computed values is done by comparison with experimental chemical shifts. Therefore, the same reference has to be used for both experimental and theoretical values. For ${ }^{1} \mathrm{H}$ and ${ }^{13} \mathrm{C}$, values are reported referenced to TMS, which has to be computed at the same level of theory as the studied compounds. For ${ }^{11} \mathrm{~B}$, as it is not possible to calculate the $\delta\left({ }^{11} \mathrm{~B}\right)$ value in the usual scale using $\mathrm{BF}_{3} \cdot \mathrm{Et}_{2} \mathrm{O}$ as an internal reference, the most used reference is $\mathrm{B}_{2} \mathrm{H}_{6}$ that has an experimental value of $16.6 \mathrm{ppm}$ in the usual scale. In the case of ${ }^{57} \mathrm{Fe}$ and ${ }^{59} \mathrm{Co}$ metal centres, the same methodology is used. For the former, ferrocene is used as reference and for the latter cobaltocenium ion is then converted to the usual aqueous $\mathrm{K}_{3}\left[\mathrm{Co}(\mathrm{CN})_{6}\right]$ scale.

Pennanen et al. ${ }^{37}$ studied paramagnetic ${ }^{11} \mathrm{~B}$ NMR metallacarborane species, both experimentally and theoretically. While DFT calculations of NMR parameters of diamagnetic compounds have become routine nowadays, the calculation of those 
parameters for paramagnetic species is barely studied. Due to unpaired electrons present in the system, computational NMR study of such species is far from routine, as the required theoretical framework as well as systematic first-principles computational tools have been developed only during the last decade. Calculation on paramagnetic metallacarboranes could prove important due to their increasing applicability in very different fields as mentioned in the introduction. Having a metal centre in the structure allows that, either in the ground state or during a reaction, the presence of paramagnetic species is not unusual in metallacarborane chemistry. Therefore, reliable methods to study such species are considered of vital importance in the community. In conclusion, computational NMR studies on metallacarboranes have been used as a substitution of X-ray crystallography to confirm geometries, although it needs to be considered that experimental NMR values are measured in solution and some discrepancies can be found between the geometry found in the liquid and solid state.

If theoretical NMR has been rather widely used for metallacarboranes, computational IR and RAMAN spectroscopy studies have not yet found yet their way into this field. So far, only one reference is found in the literature that uses computational RAMAN studies. ${ }^{38}$ In this case, the comparison between experimental and theoretical RAMAN spectra is used to determine the geometry in the solid state. Moreover, with the aid of computed values it is possible to assign all the frequencies in the spectra to the different vibrations within the molecule. It is remarkable how good the agreement between experiment and theory is and it has to be taken into account that it can be a very useful tool to study geometries of metallacarboranes in the solid state, as seen in Figure 6. 


\section{3.c) Atomic charge calculations.}

The concept of partial atomic charges has been used since the very beginning of computational chemistry. It associates molecular polarity with charge build-up or reduction on the individual atoms. This allows to ignore the more complex wave character of the electrons and to concentrate on the individual atoms; the electronic distribution in the molecule is visualized by the degree of positive or negative charge on each individual atom. The atomic charges are also often used for a qualitative understanding of the structure and reactivity of molecules. Despite their practical utility, partial atomic charges are an artificial construct without a direct link to an experimental observable and thus their magnitude depends on the computational method used. Many different methods exist to calculate partial charges but none of them is agreed as being the 'best' procedure. This is understandable because charges are used in different ways within the context of different quantitative and qualitative models in chemistry.

Five main ways to describe partial atomic charges in metallacarboranes have been used: Mulliken population analysis, natural population analysis (NPA), atoms-in-molecules AIM, Voronoi Deformation Density (VDD) and a fit to the electrostatic potential (ESP). Mulliken charges were the first to be computed as they are derived directly from the molecular orbital-linear combination of the atomic orbital (MO-LCAO) method. They were first used by Maguire et al., ${ }^{39}$ which helped to elucidate the nature of the chemical bonding between the metal centre and the carborane ligand. However, they prove to be very sensitive to the basis-set size, so that comparison of partial charges from different levels of theory is not possible. On the other hand, NPA charges converge to a stable value with increasing basis-set size. Despite having problems, as for example overestimating the magnitude of the charge, the great speed with which the charges are 
computed suggests that they will remain widely used in the field. In metallacarboranes, for example, NPA analysis has been used in many studies since $2005^{22}$ and has shown that the metal sandwiched between two dicarbollide ligands accepts a substantial amount of charge from them. In the case of AIM charges, only a few examples exist in the literature. The reason may be that the calculation of these charges is not an easy task as it is necessary to calculate atomic multipole moments to achieve a good picture of the density distribution. This calculation is time consuming and, thus, is not a method to be used routinely. VDD charges have proven to be very useful for a variety of biological, organic, and inorganic molecules. So far, they have been used by Juárez-Pérez et al., ${ }^{40}$ leading to very good results, especially in the case of hydrogen and dihydrogen interactions. In these examples, NPA charges are not realistic, yielding too extreme values that suggest much ionic character even in the case of covalent bonds, while VDD charges prove to yield chemically meaningful values (see Table 2).

The ESP fit methods are of standard use in biomolecular force-fields but are applicable in the general area of chemistry. Comparison of the NPA and the restrained-ESP (RESP) methodologies in the realm of heteroborane interactions showed that only the latter is capable of describing the hydridic nature of the boron-bound hydrogens, which is a prerequisite for the correct description of dihydrogen bonding. ${ }^{41}$ The computation of ESP charges is not restricted to biochemical studies of metallacarboranes but also to their use as synergistic agents in the extraction of radionuclide wastes. In this case, the electrostatic potential is fundamental to properly describe these compounds in the simulations at liquid-liquid extraction interfaces with a set of cations. ${ }^{42}$

As discussed above, an important feature extracted from atomic charge calculations is the bonding nature and electronic distribution in the molecule. For metallacarboranes, 
the polarity between the carbon and boron vertices due to the higher electronegativity of carbon (2.55 vs. 2.04, respectively) causes that electrons are concentrated near the carbon. This influences the different reactivity found for $\mathrm{C}$ and $\mathrm{B}$, which allows the rich chemistry found in these clusters, Figure 7. The higher negative charge found on $\mathrm{C}$ also implies that these form stronger bonds with the metal. Moreover, the charge within different $\mathrm{B}$ vertices is also different depending on their relative position in the cluster. The closer the boron atom is to the carbon the more positive it is. The opposite is also true. Concerning hydrogen atoms, when these are bonded to carbon atoms are more acidic than when are bonded to boron atoms, which are found to be hydridic, despite their atomic charge is near zero. ${ }^{43}$

There have been attempts to rationalize the reactivity of different boron vertices by considering the atomic charges. However, many reactions in boranes can be better interpreted considering that the attack takes place on the $\mathrm{B}-\mathrm{H}$ bond and not on the $\mathrm{H}$ or B atoms. Therefore, to predict which vertices are prone to react with nucleophiles or electrophiles, it is important to consider the sum of the charges on carbon or boron and the hydrogen atom. The method is named 2a-NPA and its chemical meaning is similar to the Mulliken overlapping population. This has been explained for anionic carboranes but it can be extended to metallacarboranes. ${ }^{44}$

Finally, partial atomic charge calculations can give indication on the electrochemical properties of metallacarboranes. Remarkably, by using the cluster total charge (CTC) -it is the sum of all charges on the cluster atoms - it is possible to correlate the redox potential on the metal with CTC values, since the atomic charge on the metal itself is distributed through the cluster and it is not indicative of the electron density on the metal centre. ${ }^{45}$ 


\section{3.d) Non-covalent interactions of metallacarboranes.}

In this section, non-covalent interactions involving carborane (as a model) and metallacarborane compounds are discussed. Such interactions are established between atoms, which are not linked by covalent bonds as, for example, cation-anion interactions, hydrogen and dihydrogen bonding (DHB). The nature of non-covalent interactions of metallacarboranes is dictated by their physicochemical properties. Most important is their unique amphiphilic character; they are composed of charged species $\left(\mathrm{M}^{\mathrm{I}}-\mathrm{M}^{\mathrm{IV}}\right.$ metal ions and carborane cage anions) but the total charge is delocalized over the whole molecular surface. Moreover, the slightly larger electronegativity of hydrogen in comparison with boron $(\Delta \chi=0.16)$ results in a small partial negative charge on the boron-bound hydrogens. This is manifested by the propensity of metallacarboranes to interact with positive counterions ${ }^{46}$ or positively-charged hydrogens of biomolecules via DHB. $^{41}$

Theoretical methods used for geometry optimizations, electron density studies and charge populations help to understand such interactions, and to control and develop new properties of metallacarborane compounds. Metallacarborane interactions with the surrounding molecules are specific and thus are a promising subject of study for many applications.

The interaction energy between a sodium cation $\mathrm{Na}^{+}$and $\mathrm{B}-\mathrm{H}$ bonds in carboranes was studied based on the data of high resolution X-ray diffraction study and quantum chemical calculations for the Na $\cdots \mathrm{H}-\mathrm{B}$ bonded dimer. ${ }^{47}$ It was found that the electron distribution of the $\mathrm{C}_{2} \mathrm{~B}_{3}$ face is similar to cyclopentadienyl ligand. A topological analysis of the electron density distribution function demonstrated that the $\mathrm{Na}^{+} \ldots \mathrm{H}-\mathrm{B}$ interactions are preferred to $\mathrm{Na}^{+} \ldots \mathrm{H}-\mathrm{C}$ ones. 
In another study, the $\mathrm{Na}^{+}$interactions with cobaltabisdicarbollide anion were investigated computationally by DFT in implicit solvent to explain the experimental observation of their aggregation with poly(ethylene oxide), PEO. ${ }^{48}$ Furthermore, a comparison was made with the binding of a linear ethylene oxide pentamer (a PEO model) to cobaltabisdicarbollide or $\mathrm{Na}^{+}$. The calculations suggested that the cationanion interaction between $\mathrm{Na}^{+}$and a cobaltabiscarbollide sandwich complex was actually repulsive in aqueous environment by $15.4 \mathrm{kcal} / \mathrm{mol}$, which was in agreement with the salt being a strong electrolyte. Thus, the driving force for the aggregate formation was attributed to the favorable $\mathrm{Na}^{+} /$ethylene oxide interaction $(-19 \mathrm{kcal} / \mathrm{mol})$, followed by the cobaltabisdicarbollide/ethylene oxide attraction of $-6.3 \mathrm{kcal} / \mathrm{mol}$. Structurally, the latter binding was accomplished via dihydrogen bonding. Although the modeling of solvation phenomena using implicit models might be incomplete, especially for metallacarboranes, this study is instructive in that it offered an insight into the balance of various interactions in this three-component system.

Also, cation-anion interactions can be responsible for the rotamer isomer found in the solid state for cobaltabisdicarbollide sandwich complex or cobaltabisdicarbollide tetramer cluster bound in the active site of HIV-1 protease enzyme (see below). ${ }^{49}$ The energy difference between the lowest minimum (transoid) and the highest maximum (cisoid) rotamer calculated by DFT in vacuum is around $8.7 \mathrm{kcal} / \mathrm{mol}$ and the energy barriers for their interconversion range from 3.2 to $8.3 \mathrm{kcal} / \mathrm{mol}$ but the latter value is diminished to $6.2 \mathrm{kcal} / \mathrm{mol}$ due to symmetry reasons. ${ }^{22}$ These calculations suggest that at room temperature and in solution the two dicarbollide moieties of the cobaltabisdicarbollide anion can rotate freely relative to each other around the long molecular axis. However, theoretical calculations predict the transoid rotamer as the 
most stable, while in the solid-state crystallographic structures show a clear tendency for the cisoid arrangement. ${ }^{43}$ This anomaly is probably caused by the fact that cobaltabisdicarbollide anions interact with each other using the positively and negatively charged regions on the cluster. The cisoid rotamer would be stabilized via electrostatic dihydrogen bonding, intermolecular $\mathrm{C}-\mathrm{H} \cdots \mathrm{H}-\mathrm{B}$ interactions where the partial charge of the proton in $\mathrm{C}-\mathrm{H}$ could be a good indicator to discern the rotamer disposition found in the solid state. ${ }^{43}$

Dihydrogen bonding of borane clusters $(\mathrm{B}-\mathrm{H} \cdots \mathrm{H}-\mathrm{C} / \mathrm{H}-\mathrm{N}$, etc.) is possibly the most abundant interaction in these compounds with calculated energies ranging from 4.2-7.6 $\mathrm{kcal} / \mathrm{mol}{ }^{41}$ The first dihydrogen bond of the B-H $\cdots \mathrm{H}-\mathrm{S}$ type was found responsible for the self-assembly of mercaptane-metallacarborane compounds. ${ }^{50}$ The existence of DHB interactions has been confirmed by means of Bader's atoms in molecules (QTAIM) theory. The energy of an interaction was estimated at $1.4 \mathrm{kcal} / \mathrm{mol}$. C-H $\cdots \mathrm{H}-\mathrm{B}$ interactions contributed to the overall crystal stabilization but interactions involving the SH group seemed to play a more important role in their self-assembly. Another exotic example is a crystallographic study on contacts between the $\mathrm{Si}-\mathrm{H}$ proton acceptor group and the $\mathrm{C}-\mathrm{H}$ proton donor moiety in the cobaltabisdicarbollide anion. ${ }^{40}$ The short contacts were also studied within the framework of QTAIM, using theoretical electron densities obtained by DFT methods, which allowed discriminating between short contacts and DHB interactions. The work showed a simple method to estimate bonding energies for these interactions in the scheme of Voronoi charge population.

Other examples where the non-bonding interactions play an important role are the molecular conductors based on the cobaltabisdicarbollide anion, ${ }^{51}$ their surfactant behaviour $^{42}$ and interactions with biomolecules ${ }^{52}$ (see section 4.a). 


\section{3.e) Redox potential.}

Any oxidation-reduction (redox) reaction can be divided into two half-reactions: one in which a chemical species undergoes oxidation and one in which another chemical species undergoes reduction. If a half-reaction is written as a reduction, the driving force is the reduction potential. The standard redox potential $\left(\mathrm{E}_{0}\right)$ is a fundamental property of a molecule that can determine its chemical reactivity. Electron transfer is the key in many processes of life, including oxygen binding, photosynthesis and respiration. The construction of biomimetic artificial systems lies in understanding and controlling the redox properties of the reactive species. Therefore, despite the ease to measure the redox potential experimentally, the ability to accurately predict this value is highly desirable. By computing the HOMO and LUMO of a set of chlorinated metallacarboranes it was possible to parallel the experimentally observed sequential additive potential values upon the incorporation of a new chlorine into the metallacarborane framework compounds which could be used as electron transfer molecules, as shown in Figure $8 .^{45}$

Electrochemistry in metallacarboranes has been extensively studied owing to the presence of a metal in the structure. Morris et al. ${ }^{53}$ already reported a review with electrochemical data and reasoned the importance of studying the electrochemical properties of such compounds. But it was not until the discovery of multidecker metallacarboranes and their application as potential building blocks in advanced electronic materials that electrochemistry played a key role in the field of metallacarboranes. ${ }^{54}$ Since then, many studies have appeared in the literature, and during the last decade, efforts have focused on the synthesis and characterization of new multidecker metallacarboranes incorporating different metals. Typically, their structural 
integrity is maintained upon oxidation or reduction. The development of such applications requires detailed information on the electronic structures and properties of these systems. Therefore, particular attention has to be riveted to the influence of substituents, metal oxidation states, and molecular architecture on electron delocalization between metal centers. Experimental electrochemical studies have proven very useful to acquire the necessary data to elucidate these properties. ${ }^{10,13}$ Therefore, the use of computational resources to expand the information within this field is drawing a lot of interest and experimental boron chemists will make use of this tool as a new routine.

Baik et al. ${ }^{55}$ proposed a systematic methodology to accurately calculate redox potentials using state-of-the-art computational methods. Electrochemical phenomena provide a challenge to computational chemistry because the pathway of a redox reaction can be quite complex. Efficient methods for self consistently incorporating solvation effects have been introduced that make use of a dielectric continuum to represent the bulk behaviour of the solvent. On this basis, a protocol based on the thermochemical (BornHaber) cycle has been successfully applied both to organic systems and to organometallic complexes. For the latter, the computational cost and difficulty causes that the typical error ranges between $0.2-0.3 \mathrm{~V}$.

However, the difficulty to accurately compute rather large systems makes that its use in metallacarboranes has so far been reduced to one example. ${ }^{56}$ There, irrespective of the solvation model (PCM or COSMO), the theory satisfactorily predicts the potentials with a maximum deviation from experimental value being $0.26 \mathrm{~V}$ for $\mathrm{PCM}$ and $0.22 \mathrm{~V}$ for COSMO. Although the error is within the typical range, an improvement of the 
calculations would be needed to use the calculation of theoretical redox potentials as a practical tool.

Important information can be gathered from this type of calculations like the structural changes accompanying redox processes. For example, elongation of M-ligand distance upon reduction or oxidation or distortion of arene-type ligands can be obtained using the methodology. Other information can be obtained by comparison of redox potentials of metal complexes as they are often used to evaluate ligand electronic effects.

\section{3.f) Calculation of UV-Vis spectra and NLO properties.}

\section{3.f.1) Calculated UV-Vis spectra}

Excitation energies and oscillator strengths using TD-DFT were calculated at B3LYP level for the cobaltabisdicarbollide anion. ${ }^{22}$ The largest intensity is computed for a band at $277 \mathrm{~nm}$, a transition from high-lying carborane-skeleton bonding MO's into the LUMO/LUMO+1 pair, in very good agreement with the experimental result. It is interesting to note that the transoid rotamer presents calculated absorptions around 445 $\mathrm{nm}$ of zero intensity. This absorption is the responsible of the orange colour of solids and solutions of cobaltabisdicarbollide. However, when the electronic transitions of the cisoid rotamer are computed, a small absorption appears at around $451 \mathrm{~nm}$.

The Fe(II)-bistricarbollide has been found as an effective structural element for liquid crystals. ${ }^{57}$ The ZINDO semiempirical method has been used to calculate transition energies in these metallomesogen compounds. The experimental electronic absorption spectrum agrees fairly well with calculations. The most intense absorption calculated at $301 \mathrm{~nm}$ results from a combination of occupied orbitals localized on the $\pi$-aromatic fragment of the metallomesogen and a small contribution from the Fe atom (HOMO). 


\section{3.f.2) Second-order nonlinear optical (NLO) coefficient calculations.}

B3LYP method was employed to calculate polarizability and second-order NLO coefficients of 7-vertex cobaltacarborane metallocenyl derivative isomers ${ }^{58}$ and of 13 vertex metallacarboranes $4,1,6-\mathrm{MC}_{2} \mathrm{~B}_{10} \mathrm{H}_{12} \cdot{ }^{59}$ The authors found in calculations that a small frontier molecular orbital energy gap results in larger second-order NLO coefficient. In 7-vertex compounds the second-order NLO response is more powerful when one substituent containing electron donor group and one substituent containing electron acceptor group are located at meta position. The metallacarborane can be able to push or pull an electron depending of the pending group character. Basis sets had only slight effect on NLO coefficient calculation. 


\section{4.- Interactions in real life experiments.}

\section{4.a) Interactions in biological systems. Anti-cancer agents and HIV-1 protease}

\section{inhibitors.}

Metallacarboranes have recently been arousing a growing interest for their potential to be used in medicinal chemistry as novel pharmacophores or radioimaging agents. ${ }^{2,52,60}$ The versatility of metallacarboranes is given by both the wide array of the existing carborane cages used as ligands and the possibility to utilize a large variability of (transition) metal ions. In this manner, the shape and charge of the metallacarboranes can be tailored to specific aims. Furthermore, for the class of metal bisdicarbollides, the broadly developed exo-substitution chemistry can be utilized to append organic groups or linkers of desired polarity or size.

Some classes of metallacarboranes have potential pharmacological advantages over the traditional organic chemistry drugs. First, the icosahedral boron cluster framework is extremely stable to physical (heat), chemical (oxidation) and biological (enzyme degradation) stimuli, which could result in its favorable pharmacokinetic profile. Second, due to its chemical composition distinct from the biological systems, metallacarboranes should not interfere with the cellular mechanisms in the manner we know from biology. This is probably why some classes of metallacarboranes tested in the human body are nontoxic.

As mentioned above, one advantage of metallacarboranes as pharmacophores is that their total charge can be modulated by exchanging the metal identity. ${ }^{61}$ On the other hand, their disadvantage for a pharmaceutical use is their low solubility in water and a tendency to aggregate. ${ }^{46}$ These phenomena, however, can be supressed by the use of suitable biocompatible carriers - excipients. ${ }^{62}$ 
A detailed understanding of metallacarborane interactions in biological systems is a crucial prerequisite for a successful rational drug design. Computational methods are a unique tool to investigate the structures and energies associated with these interactions. Due to the chemically unique nature of metallacarboranes, quantum chemical (QM) calculations are required to describe reliably such effects as, for example charge delocalization or transfer.

A useful practice is to first study the metallacarborane properties and interactions in model systems in vacuum and only then in biomolecular complexes including the solvent. This methodological build-up can be documented by the computational studies of a series of metal bisdicarbollides. As a model for the carborane cages, the $\left[\mathrm{CB}_{11} \mathrm{H}_{12}\right]^{-}$ molecule was used and its interactions with model amino acids were investigated in vacuum using DFT and MP2 optimizations and single-point calculations. ${ }^{41}$ The formation of dihydrogen bonds and their preferential location in the antipodal part of the cage ( $\mathrm{B}$ atom opposite to $\mathrm{C}$ atom) were rationalized using the calculated RESP atomic charges (Figure 9). Shifting to larger molecules, a series of substituted metallabisdicarbollides $-\left[3,3^{\prime}-\mathrm{M}-\left(1,2-\mathrm{C}_{2} \mathrm{~B}_{9} \mathrm{H}_{11}\right)_{2}\right]^{\mathrm{n}}$ where $\mathrm{M} / \mathrm{n}$ stands for $\mathrm{Fe} /-2$, Co/-1 and $\mathrm{Ni} / 0$ - was treated using a similar methodology but enhanced with an implicit solvent model. ${ }^{61}$ The interacting partners (amino acids) were made larger to become model peptides. This study showed the intricate balance of gas-phase interaction energies and desolvation penalties upon complex formation.

An important prerequisite for investigating metallacarborane interactions in biological systems is the understanding of their rotamer preferences. Thus, the DFT study of the relative stabilities and interconversion barriers of the transoid, gauche and cisoid rotamers of the $\left[3,3^{\prime}-\mathrm{Co}-\left(1,2-\mathrm{C}_{2} \mathrm{~B}_{9} \mathrm{H}_{11}\right)_{2}\right]^{-}$cobalta bisdicarbollide anion (Figure 10.a) ${ }^{22}$ 
was crucial for the interpretation of hybrid quantum chemical/molecular mechanical (QM/MM) calculations on a large biomolecular complex of four cobaltabisdicarbollide molecules bound to two dimers of HIV-1 protease (Figure 10.b). ${ }^{49}$ A comparison showed the effect of the metallacarborane surroundings in the complex (the protein, solvent and counterions) on the energy profiles of the rotation of the dicarbollide moieties.

One of the advantages of computational procedures is that they can become a unique source of information in cases where the experimental structural data is incomplete. This was the case of a crystallographic structure of a complex between HIV-1 protease and linker-substituted dual-cage cobaltabisdicarbollides. ${ }^{63}$ While the electron-density maps for the protein and the metallacarborane cage were clear, the linker was disordered due to its flexibility. Sampling of conformations accessible to the linker in the cavity of the enzyme was carried out using molecular dynamics (MD) simulations. Reoptimizations of 20 snapshots from the MD run were performed using a $\mathrm{QM} / \mathrm{MM}$ methodology were subsequently performed. This resulted in finding four low-energy conformers (Figure 11), which were suggested to be co-populated in the complex and used for the interpretation of the binding affinities and further inhibitor design. ${ }^{63,64}$ In the following text we will review the advances in the studies of metallacarboranes in two pharmacological areas, the anti-cancer agents including boron neutron capture therapy (BNCT) and the inhibition of human immunodeficiency virus 1 (HIV-1) protease in anti-AIDS drug research. Both topics have been mentioned in several recent reviews on the medicinal chemistry of carboranes, ${ }^{60,65,66}$ or enzyme inhibition ${ }^{67}$ and the latter is also treated in much detail in a book chapter. ${ }^{64}$ 
The best established role of boron-based compounds in medicine is as agents for the boron neutron capture therapy (BNCT) of cancer. ${ }^{66}$ Although this area has been reserved mainly to substituted 12 -vertex boranes, several metallacarborane derivatives cobaltabisdicarbollide conjugates with nucleosides- have also been tested and shown to accumulate in the cells and to be nontoxic. ${ }^{65}$ Furthemore, conjugates of metallacarboranes with porphyrins hold promise to be useful in the dual photodynamic therapy (PDT)/BNCT of cancer. ${ }^{66}$

Cytotoxic activities against various cancer cell lines (mostly leukemia and lymphoma) were found for small metallacarborane complexes of the nido- $\mathrm{C}_{2} \mathrm{~B}_{4}$ or nido- $\mathrm{C}_{3} \mathrm{~B}_{7}$ types (Figure 1.i) based on the activities of analogous metallocene sandwiches. ${ }^{2}$ Metallacarboranes complexing a range of metals (Fe, Co, Ta, Mo, W, V, Nb) had these properties. The mode of action was tracked down to the inhibition of the purine and thus the RNA/DNA synthesis.

Radioimaging is another field of medicine where various substituted metallacarboranes may find their applications. Two modern and sensitive approaches (as opposed to the traditional magnetic resonance imaging) are the positron emission tomography (PET) and the single photon emission computed tomography (SPECT). ${ }^{60}$ A suitable radionuclide to be used is ${ }^{99 \mathrm{~m}} \mathrm{Tc}$ due to its convenient half-life of 6 hours. Because there is no non-radioactive nuclide of technetium, its effects are investigated in the congener rhenium complexes. Radiolabelling of several nido-carboranes with ${ }^{99 \mathrm{~m}} \mathrm{Tc}$ or the Re metals (Figure 1.j) have been carried out and the binding of these metallacarboranes to various cellular receptors (e.g., estrogen receptor or serotonine receptor) together with their biodistribution was tested. ${ }^{60}$ Another structural possibility is the sandwiching of a radioactive metal ion in a Venus Flytrap type metallacarborane (Figure 1.k). Such a 
metallacarborane was attached to an antibody and was shown to localize in the tumor tissue. ${ }^{2}$ These results hold promise for the possible future use.

The second major area of medicinal applications of metallacarboranes is the inhibition of HIV-1 protease (PR). Because this enzyme is crucial for the life cycle of HIV and indispensable for the spread of infectious particles in the human body, its inhibition by peptide-like or non-peptidic compounds have proven to be an effective way of combating AIDS. However, an urgent need for novel inhibitor scaffolds exists due to the problems of resistance and side effects. ${ }^{67}$

A class of substituted metallacarboranes, specifically metal bisdicarbollides, has been discovered as potent, specific, competitive and nontoxic inhibitors of HIV-1 protease. $^{52}$ The compounds attained nanomolar inhibition constants and had also some activity in tissue cultures. The X-ray crystallographic structure of the complex of HIV-1 protease with bound parent compound cobaltabisdicarbollide (Figure 12), explained the potency due to their novel binding mode. Two molecules of this parental metallacarborane bound in an asymmetrical mode into the $\mathrm{C}_{2}$-symmetrical binding cavity of $\mathrm{PR}^{52}$ The nature of the interaction has been rationalized using quantum mechanical calculations as being composed of B-H $\cdots \mathrm{H}-\mathrm{C}$ dihydrogen bonds $(c f \text {. Figure } 9)^{41}$ and $\mathrm{B}-\mathrm{H} \cdots \mathrm{Na}^{+}$ interactions. ${ }^{49}$ This novel type of binding is the reason for the sustained potency of these metallacarboranes against resistant mutant PRs. ${ }^{68}$

To further increase the potency of metallacarboranes, rational design based on the X-ray structure yielded a series of substituted double/triple cluster compounds with $\mathrm{IC}_{50}$ values in the nanomolar range. ${ }^{63,64}$ The X-ray structure showed the two metallacarborane clusters bound symmetrically in the enzyme and the linker had no continuous electron density which suggested its flexibility. Indeed, using dynamics and 
QM/MM modeling several stable conformations of the linker were found which also revealed a possible interaction of the positively charged $\mathrm{NH}_{2}$ group of the linker with the anionic catalytic aspartates of HIV PR (Figure 11). ${ }^{63}$ Some of these compounds displayed non-competitive mode of inhibition. ${ }^{63,64}$ This may be linked to their larger size and the possibility of finding distant epitopes on the surface of HIV PR and/or aggregation behavior. $^{46}$

\section{4.b) Hydrogen storage.}

For hydrogen storage graphitic materials doped with transition metals have long been used. However, they show aggregation problems and a loss of storage capacity. Thus novel materials were searched and metallacarboranes presented a new possible option based on DFT calculations. ${ }^{69}$ The rationale behind was that if the metal is bonded to sub- or icosahedral carborane cages then the metal could be maintained isolated and aggregation is prevented. A DFT study was performed on the first row of transition metal atoms and it was found that $\mathrm{Sc}$ and Ti maximized the $\mathrm{H}_{2}$ storage until $8 \mathrm{wt} \%$ profiles. ${ }^{69}$ The studied transition metal semi-sandwich could bind up to $5 \mathrm{H}_{2}$-molecules. The average calculated binding energy is $\sim 0.3 \mathrm{eV}$ that lies within the reversible adsorption range at ambient conditions. The prevalent interaction between $\mathrm{H}_{2}$ and metal center is the Kubas interaction, which is between strong chemisorption and weak physisorption. The $\sigma$-bonding electron pair of the $\mathrm{H}_{2}$ molecule interacts with empty $\mathrm{d}$ orbital of a metal and a back-donation from a filled metal d-orbital to the $\sigma^{*}$ orbital of $\mathrm{H}-\mathrm{H}$ bond is produced. An excess of back-donation elongates the $\mathrm{H}_{2}$ bond and finally it could be an oxidative addition to the central metal. According to the authors, these 
simulated materials could adsorb up to $8 \mathrm{wt} \%$ of hydrogen, which easily meet the material-based DOE targets for 2015.

\section{4.c) Radionuclide extraction, surfactant behaviour in aqueous phase.}

Since the first synthesis of metallacarboranes, cobaltabisdicarbollide and its halogenated derivatives have found important applications in the field of radionuclide extraction from nuclear waste solutions. ${ }^{70}$ Nuclear waste management processes that are presently in operation start with the PUREX process in which almost all uranium and plutonium is separated from the depleted fuel. The remaining liquid after the removal of uranium and plutonium is high-level liquid waste (HLLW), containing about $3 \%$ of the used fuel in the form of fission products and minor actinides (Np, Am, Cm). The long lasting radioactivity $\left(\mathrm{T}_{1 / 2}=10^{3}-10^{4}\right.$ years) of the latter makes storage of HLLW a serious environmental problem which is also economically unfavourable. The radioactivity can be reduced by neutron irradiation of the minor actinides into short-lived $\left(\mathrm{T}_{1 / 2}=10^{1}\right.$ years) nuclides. However, lanthanides and especially Sm, Gd, and Eu have a higher affinity to capture neutrons than actinides reducing the effectiveness of the process. Therefore, a method to separate the actinides from the chemically similar but relatively harmless lanthanides is required. Many methods have been described in the literature depending on the ingredients of the cocktail used in the extraction process.

At early stages, metallacarboranes but mainly chlorinated cobaltabisdicarbollide $\left(\mathrm{CCD}^{-}\right)$ was used in the UNEX (Universal Extraction) process in combination with polyethylene glycol and CMPO in aromatic polar solvents. Thereafter, $\mathrm{CCD}^{-}$has been used in combination with other type of molecules leading to significant extraction enhancement. More recently, the use of brominated cobaltabisdicarbollide has also been tested leading 
to an enormous increase of the extraction ability. Remarkably, around $35 \%$ of the papers containing the word dicarbollide are related to extraction tests. However, no clear explanation for this improved extraction efficiency has been proposed at a molecular level.

In order to understand what happens at the nanoscopic level in such heterogeneous complex systems and to gain microscopic insights into this synergistic effect, Wipff et al. have studied the system by using molecular dynamics (MD) calculations. ${ }^{71}$ It must be reminded that on one hand, force-field MD is an ideal simulation tool to study phase separations and other phenomena on the mesoscopic scale but on the other hand, it inevitably represents an approximate method by which some molecular features of the $\mathrm{CCD}^{-}$species (e.g. the dicarbollide rotation, the charge transfer to the metal) will not be described correctly. In 2004, this group studied the synergistic mixture of a CMPOcontaining calixarene with $\mathrm{CCD}^{-}$species at a water-'oil' interface, where 'oil' was modelled by chloroform. The goal was to find out the distribution of the free ligands (L), of a typical complex $\mathrm{EuL}^{3+}$, of $\mathrm{CCD}^{-}$species, and of the $\mathrm{Eu}(\mathrm{CCD})_{3}$ salt in different combinations. The first important result from this paper was the notion of the high surface activity of the $\mathrm{CCD}^{-}$anions. The free ligand $\mathrm{L}$ and its $\mathrm{EuL}^{3+}$ complex were also surface active, which strongly suggested that complexation took place at the interface, and that this could be promoted by $\mathrm{CCD}^{-}$anions. Although hard ions were generally repelled from the interface, the interfacial film formed by $\mathrm{CCD}^{-}$created a negative potential, attracting the cations and allowing their capture by the ligands as shown in Figure 13. Another issue concerned the driving force for diffusion of the complexes from the interface to oil. At high concentrations, $\mathrm{CCD}^{-}$saturated the interface and 
attracted the $\mathrm{EuL}^{3+}$ complex. Then, the complex interacted less with water at the interface than it did in the bulk solution.

In $2006,{ }^{42}$ the study was expanded to other cobaltabisdicarbollide derivatives, [3,3'-Co$\left.\left(1,2-\mathrm{C}_{2} \mathrm{~B}_{9} \mathrm{H}_{8} \mathrm{X}_{3}\right)_{2}\right]^{-}$with $\mathrm{X}=\mathrm{H}, \mathrm{Me}, \mathrm{Cl}$ or Br. Surprisingly, simulations of [3,3'-Co-(1,2$\left.\left.\mathrm{C}_{2} \mathrm{~B}_{9} \mathrm{H}_{8} \mathrm{X}_{3}\right)_{2}\right]^{-}$species showed a surfactant type behavior of the dicarbollide anions, which, although lacking the classical amphiphilic topology, tended to self-assemble in aqueous solution as well as at the aqueous interface. Moreover, after the paper was published, there appeared a report on light scattering and microscopic studies of concentrated sodium and caesium salt solutions of cobaltabisdicarbollide where was observed an association of these anions in aqueous solutions. ${ }^{46}$ About $80 \%$ of sodium salt formed large aggregates (of up to $115 \mathrm{~nm}$ ) and a small fraction of molecules dissolved molecularly or formed small aggregates. The behavior of nanoaggregates was found to be fairly complex and to depend on the concentration and aging of the solutions and on the counterions. Nonetheless, experimental and simulated results were hardly comparable taking into account that these data were obtained in different conditions and at a mesoscopic scale. However, both approaches are consistent with each other, showing the formation of anionic clusters stabilized by counterions by different extents if one compares $\mathrm{Cs}^{+}$to $\mathrm{H}_{3} \mathrm{O}^{+}$. More recently, a thorough experimental study has been published related to $\mathrm{H}\left[3,3^{\prime}-\mathrm{Co}-\left(1,2-\mathrm{C}_{2} \mathrm{~B}_{9} \mathrm{H}_{11}\right)_{2}\right]$. The combination of powder X-ray, small- and wide- angle and neutron scattering (SAXS, WAXS and SANS) and cryo-transmission electron microscopy (cryo-TEM) led to the conclusion that $\left[3,3^{\prime} \text { '-Co- }\left(1,2-\mathrm{C}_{2} \mathrm{~B}_{9} \mathrm{H}_{11}\right)_{2}\right]^{-}$species formed different type of aggregates depending on the concentration. For very dilute samples, vesicles with a radius of $19 \mathrm{~nm}$ were 
observed. On the other hand, at higher concentrations micelles began to form resulting in coexistence with the vesicles as clearly shown in Figure 14. ${ }^{72}$

Finally, in 2007 new MD simulations were done including a new type of ligand, the nitrogen containing BTP. ${ }^{42,73}$ The major difference from previous studies was the use of other organic solvents as "oil" phases. Instead of chloroform, the use of octanol and nitrobenzene allowed the possibility to extend the knowledge to new biphasic systems. In the case of octanol, it is known that its heterogeneous structure, comprising apolar and polar domains, allowed for dual specific interactions with hydrophobic, heterogeneous solutes. On the other hand, the selection of nitrobenzene was based on its high dielectric constant that made it possible to solubilise ions and, in particular, $\mathrm{CCD}^{-}$ salts. It also has a low miscibility with water, but more importantly, it has been used as a receiving phase in ion extraction. As a result for both solvents, it was found that without CCDs, the complex was trapped at the interface, while when the CCDs were concentrated enough, the complex was extracted to the organic phase. The results were comparable to those obtained with chloroform and demonstrated the synergistic effect of CCDs in liquid-liquid extraction processes. 


\section{Conclusions}

The impact of the nowadays available theoretical tools on the study of metallacarboranes has been shown in this Tutorial Review. It has been demonstrated that theory can bring very useful information on the nature and reactivity of these nonconventional, highly tunable inorganic complexes with rich substitution chemistry. The most frequently used theoretical methods have been summarized so that they could be applied by experimental chemists. Remarkably, many papers included in this review combine experimental and theoretical studies, even the first ones published more than 15 years ago. This is extraordinary because it shows the amount of data that could and can be extracted from calculations. The contribution of these studies becomes especially relevant when details of the system (such as structures or energies) could not be determined experimentally, but could be extracted using the theoretical approach. The possibility of using faster computers and improved theoretical methodologies also opens the door to calculations of even more difficult molecular properties. Therefore, the application of theory to metallacarboranes needs to become routine to complement the experimental data.

Some specific cases have been analyzed as an example of the power of computational chemistry. Indeed, the understanding of the interactions of metallacarboranes with other molecules has a special significance in their use in medicine and the treatment of radionuclide wastes. In recent years numerous studies have explored their potential as anti-cancer agents including BNCT and radioimaging as well as HIV-1 protease inhibitors. Quantum chemical calculations are a unique tool to properly describe the electronic structure of metallacarboranes and their interactions with biomolecules, thus offering molecular interpretation and rational design of pharmacophores. On the other 
hand, force-field-based molecular dynamics employed in the application of metallacarboranes in radionuclide extraction has discerned their real function as synergistic complexes. It has been demonstrated that the ability to interact with radionuclide cations at the interface between organic and aqueous solvents is critical for good extraction coefficients, and this was first realized based on theoretical calculations. This contribution aims to summarize the theoretical studies made up to date on these intriguing molecules and encourages the reader to apply the theoretical approach in their experimental studies. The authors have strived to show that a lot of data complementing experimental results can be extracted with relatively easy calculations. Moreover, information from e.g. the calculation of partial atomic charges can be used to discern the nature of the interactions in their crystal structures. Furthermore, simulation of NMR spectra can be used to complement the spectroscopic techniques employed experimentally to obtain unambiguously the determination of the structures of the studied molecules.

\section{Acknowledgements}

This work was supported by Spanish Ministerio de Ciencia e Innovación (CTQ201016237) and the Generalitat de Catalunya 2009/SGR/00279. The access to the computational facilities of Centre de Serveis Científics i Acadèmics de Catalunya (CESCA) is gratefully acknowledged. M.L. gratefully acknowledges the financial support from the Academy of Sciences of the Czech Republic (Z40550506) and from the Grant Agency of the Academy of Sciences of the Czech Republic (IAAX00320901). 


\section{Figures}

Figure 1. Schematic structures of endo-metallacarboranes: a) commocobaltabisdicarbollide anion, b) metallaborane with Ir atom in apical or basal position, c) carbon-apart or carbon-adjacent metallacarborane isomers, d) triple and doubledecker cobaltacarboranes, e) cymantrene analogue compound with tricarbadecaboranyl ligand, f) dianion $\left[\eta^{5}-7,8-\mathrm{C}_{2} \mathrm{~B}_{9} \mathrm{H}_{11}\right]^{2-}$ stabilizing an $\operatorname{Ir}(\mathrm{V})$ metal center for the $\mathrm{C}-\mathrm{H}$ bond activation, g) experimentally known geometries of 13-vertex clusters based on carborane, h) 14-vertex bimetallic closo-ruthenacarborane $(\mathrm{M}=\mathrm{Ru})$, i) nido- $\mathrm{C}_{2} \mathrm{~B}_{4}$ or nido- $\mathrm{C}_{3} \mathrm{~B}_{7}$ types: (M=Fe, Co, Ta, Mo, $\left.\left.\mathrm{W}, \mathrm{V}, \mathrm{Nb}\right), \mathrm{j}\right)$ nido-carboranes with ${ }^{99 \mathrm{~m}} \mathrm{Tc}$ or $\mathrm{Re}$ metals, k) Venus Flytrap type metallacarborane ( $\mathrm{M}=\mathrm{Co}, \mathrm{X}=\mathrm{O}, \mathrm{S}, \mathrm{SO} 2)$.

Figure 2. SOMO probability 3D contour plot obtained from DFT calculations. reproduced from Ref. 9. with permission of The Royal Society of Chemistry. http://dx.doi.org/10.1039/B304101H

Figure 3. Frontier orbitals for $\left[\mathrm{SnB}_{11} \mathrm{H}_{11}\right]^{2-},\left[\mathrm{SnCB}_{10} \mathrm{H}_{11}\right]^{-}$, and 3-Sn-1,2- $\mathrm{C}_{2} \mathrm{~B}_{9} \mathrm{H}_{11}$. Energy levels in eV. Adapted and reproduced from Ref. 15 with permission of NRC Research Press. http://dx.doi.org/10.1139/v08-081

Figure 4. Relative stability of different dicarbollide ligand isomers. Graph from own elaboration using data from Ref. 22 and 31.

Figure 5. Schematic representations of experimental (bottom) and theoretical ${ }^{11}$ B NMR spectra for the cobaltabisdicarbollide anion computed with different density functional methods. Reproduced from Ref. 22 with permission of John Wiley \& Sons Ltd. http://dx.doi.org/10.1002/chem.200401202

Figure 6. Calculated Raman spectra of both anion conformations together with the 
experimental spectrum of the reference salt $\mathrm{Na}\left[3,3^{\prime}-\mathrm{Co}-\left(1,2-\mathrm{C}_{2} \mathrm{~B}_{9} \mathrm{H}_{11}\right)_{2}\right]$. Reproduced from Ref. 38 with permission of Elsevier.

http://dx.doi.org/10.1016/j.molstruc.2010.03.034

Figure 7. Electrostatic potential on the van der Waals surface of the cisoid rotamer of [3,3'-Co-(1,2- $\left.\left.\mathrm{C}_{2} \mathrm{~B}_{9} \mathrm{H}_{11}\right)_{2}\right]^{-}$. Reproduced from Ref. 43 with permission of John Wiley \& Sons Ltd.

http://dx.doi.org/10.1016/10.1002/ejic.201000157

Figure 8. Metallacarboranes as sequential additive potential compounds which could be used as electron transfer molecules. Reproduced from Ref. 45 with permission of John Wiley \& Sons Ltd.

http://dx.doi.org/10.1002/chem.200902558

Figure 9. Dihydrogen bonds between $\mathrm{CB}_{11} \mathrm{H}_{12}{ }^{-}$and glycine. The preference for the antipodal part of the cage ( $\mathrm{B}$ atom opposite to $\mathrm{C}$ atom) is rationalized using the calculated RESP atomic charges (shown for the interacting hydrogens). Hydrogen $\cdots$ hydrogen distances are in $\AA$. The structure was obtained by quantum chemical optimization on the MP2/cc-pVDZ level. Reprinted from Ref. 41 with permission of John Wiley \& Sons Ltd.

http://dx.doi.org/10.1002/cphc.200500648

Figure 10. The relative stabilities and interconversion barriers $(\mathrm{kcal} / \mathrm{mol})$ of the cobaltabisdicarbollide $\left[3,3^{\prime}-\mathrm{Co}-\left(1,2-\mathrm{C}_{2} \mathrm{~B}_{9} \mathrm{H}_{11}\right)_{2}\right]^{-}$rotamers calculated at the DFT-D level. The dihedral angle $\theta$ represents the $\operatorname{cisoid}\left(\theta=36\right.$ and $\left.324^{\circ}\right)$, gauche $(\theta=108$ and $\left.252^{\circ}\right)$ and transoid $\left(\theta=0^{\circ}\right)$ rotamers. a) free metallacarborane in vacuum. Reproduced from Ref. 22 with permission of John Wiley \& Sons Ltd.

http://dx.doi.org/10.1002/chem.200401202 
and b) tetramer of metallacarboranes in HIV-1 PR. Five differently rotated positions are shown in colours. The huge impact of the protein surroundings including two sodium counterions is observed. Reprinted (adapted) with permission from Ref. 49. Copyright (2008) American Chemical Society.

http://dx.doi.org/10.1021/jp803528w

Figure 11. Four low-energy conformers of the modelled linker in the crystal structure of the complex between HIV-1 PR and a linker-substituted dual-cage cobaltabisdicarbollide. Distances to the catalytic aspartic acid carboxylates in $\AA$ are shown. Reprinted (adapted) with permission from Ref. 63. Copyright (2009) American Chemical Society..

http://dx.doi.org/10.1021/jm9011388

Figure 12. The X-ray structure of the complex between HIV-1 protease and [3,3'-Co$\left.\left(1,2-\mathrm{C}_{2} \mathrm{~B}_{9} \mathrm{H}_{11}\right)_{2}\right]^{-}$metallacarborane. Reprinted from Ref. 52. Copyright (2005) National Academy of Sciences, USA.

http://dx.doi.org/10.1073/pnas.0507577102

Figure 13. System A $(9 \mathrm{~L})$ at the interface, starting with a $3 \times 3$ grid parallel or perpendicular to the interface. Snapshots at the beginning (0 ns) and at the end of the simulation. The water and chloroform solvents are shown side by side for clarity. Reproduced from Ref. 71 with permission of Elsevier.

http://dx.doi.org/10.1016/j.crci.2004.03.014

Figure 14. a) SANS spectra of $\mathrm{H}\left[3,3^{\prime}-\mathrm{Co}-\left(1,2-\mathrm{C}_{2} \mathrm{~B}_{9} \mathrm{H}_{11}\right)_{2}\right]$ in $\mathrm{D}_{2} \mathrm{O}$ at 0.19 (口) and $33.3 \% \mathrm{v} / \mathrm{v}(\Delta)$. Solid lines present the best fit obtained by combining two populations of spherical objects: 1) vesicles with polydisperse radius $(25 \mathrm{~nm})$ and constant wall thickness $(1.16 \mathrm{~nm})$, and 2) spherical micelles of $1.16 \mathrm{~nm}$ radius that interact through a 
hard-sphere potential. Reproduced from Ref. 72 with permission of John Wiley \& Sons Ltd.

http://dx.doi.org/10.1002/anie.201100410

\section{Tables}

Table 1. Acronyms used in the present work.

Table 2. VDD, NPA and RESP charges on hydrogen atoms (au) of selected organic and boron-containing molecules. 
Table 1. Acronyms used in the present work.

$\mathrm{ADF}$

AIDS

B3LYP

BNCT

BP86

BTP

CCD

CMPO

COSMO

$\mathrm{Cp}$

CTC

DFT

DHB

DOE

EDA

GIAO

$\mathrm{HF}$

HIV-1

HLLW

HOMO

IGLO
Amsterdam Density Functional

Acquired Immunodeficiency Syndrome

Hybrid Density Functional

Boron Neutron Capture Therapy

Hybrid Density Functional

2,6-bis(5,6-isopropyl-1,2,4-triazin-3-yl)pyridine ligand

Chlorinated cobaltabisdicarbollide

(N,N-dialkylcarbamoylmethyl)dialkylphosphine oxides

Conductor-like Screening Model for solvent effects

Cyclopentadienyl

Cluster Total Charge

Density Functional Theory

Dihydrogen Bond

Department of Energy (USA)

Energy Decomposition Analysis

Gauge-Including Atomic Orbital method

Hartree-Fock method

Human Immunodeficiency Virus Type 1

High-level liquid waste

Highest -Occupied Molecular Orbital

Individual Gauge for Localized molecular orbitals method 
IR

LUMO

MD

MDB

MNDO

MP2

NLO

NMR

NPA

ORCA

PCM

PDT

PEO

PET

PR

PUREX

$\mathrm{QM} / \mathrm{MM}$

QTAIM

RESP

SANS

SAXS

SCF
Infrared Spectroscopy

Lowest Unoccupied Molecular Orbital

Molecular Dynamics

Metal bis dicarbollides compounds

Modified Neglect of Differential Overlap method

Second order Møller-Plesset perturbation theory

Non-Linear Optical

Nuclear Magnetic Resonance spectroscopy

Natural Population Analysis

general purpose tool for quantum chemistry with specific

emphasis on spectroscopic properties

Polarizable Continuum Model for solvation effects

Photodynamic Therapy

Poly(ethylene oxide)

Positron Emission Tomography

Protease of HIV-1

Plutonium - Uranium Extraction process

Quantum Mechanics/Molecular Mechanics method

Quantum Theory of Atoms in Molecules

Restrained-electrostatic Potential method

Small-angle neutron scattering

Small-angle X-ray scattering

Self-Consistent Field method 
Spin Orbit

SOMO

Singly occupied molecular orbital

SPECT

Single Photon Emission Computed Tomography

TD-DFT

Time dependent DFT

TEM

Transmission electron microscopy

TMS

Tetramethylsilane

UNEX

Universal Extraction process

VDD

Voronoi Deformation Density method

WAXS

Wide-Angle X-ray Scattering

ZINDO

Semi-Empirical Quantum Chemistry Method

ZORA

Zero Order Regular Approximation for relativistic effects 
Table 2. VDD, NPA and RESP charges on hydrogen atoms (au) of selected organic and boron-containing molecules.

\begin{tabular}{|c|c|c|c|}
\hline & $\mathrm{VDD}^{\mathrm{a}}$ & $\mathrm{NPA}^{\mathrm{b}}$ & $\mathrm{RESP}^{\mathrm{c}}$ \\
\hline Methane & +0.022 & +0.196 & +0.072 \\
\hline Ethene & +0.037 & +0.178 & +0.165 \\
\hline Ethyne & +0.098 & +0.223 & +0.294 \\
\hline Benzene & +0.046 & +0.202 & +0.138 \\
\hline $\mathrm{SiH}_{4}$ & -0.063 & -0.150 & -0.192 \\
\hline $\mathrm{C}_{\mathrm{c}}-\mathrm{H}^{\mathrm{d}}$ & +0.125 & +0.292 & +0.10 \\
\hline $\mathrm{B}-\mathrm{H}^{\mathrm{e}}$ & $-0.033 \pm 0.006$ & $0.048 \pm 0.007$ & $-0.115 \pm 0.017$ \\
\hline \multicolumn{4}{|c|}{ a: Optimized structures at BP86/TZ2P ${ }^{40}$} \\
\hline \multicolumn{4}{|c|}{ b: Optimized structures at B3LYP/6-311G(d,p) (Gaussian 09, Revision A.02) } \\
\hline \multicolumn{4}{|c|}{ c: Optimized structures at HF/6-31G* } \\
\hline \multicolumn{4}{|c|}{$\mathrm{d}$ : Protonic hydrogen in $\left[3,3^{\prime}-\mathrm{Co}-\left(1,2-\mathrm{C}_{2} \mathrm{~B}_{9} \mathrm{H}_{11}\right)_{2}\right]^{-}$} \\
\hline
\end{tabular}




\section{References}

1 C. E. Housecroft, in Encyclopedia of Inorganic Chemistry, John Wiley \& Sons, Ltd, 2008.

2 R. N. Grimes, Coord. Chem. Rev., 2000, 200, 773-811.

3 R. Gautier, J.-F. Halet and J.-Y. Saillard, Computational Methods: Transition Metal Clusters, John Wiley \& Sons, Ltd, 2005.

4 O. Shameema and E. D. Jemmis, Encyclopedia of Inorganic Chemistry. Computational Studies: Boranes, John Wiley \& Sons, Ltd, 2005.

5 A. M. Mebel, D. G. Musaev, N. Koga and K. Morokuma, Bull. Chem. Soc. Jpn., 1993, 66, 3259-3270.

6 J. A. Maguire, N. S. Hosmane, A. K. Saxena, H. M. Zhang and T. G. Gray, Phosphorus Sulfur and Silicon and the Related Elements, 1994, 87, 129-137.

7 T. V. Timofeeva, U. Mazurek and N. L. Allinger, THEOCHEM, 1996, 363, 35-42.

8 M. B. Ezhova, H. M. Zhang, J. A. Maguire and N. S. Hosmane, J. Organomet. Chem., 1998, 550, 409-422.

9 S. Du, R. D. Farley, J. N. Harvey, J. C. Jeffery, J. A. Kautz, J. P. Maher, T. D. McGrath, D. M. Murphy, T. Riis-Johannessen and F. G. A. Stone, Chem. Commun., 2003, 2003, 1846-1847.

10 F. F. de Biani, M. Corsini, P. Zanello, H. J. Yao, M. E. Bluhm and R. N. Grimes, J. Am. Chem. Soc., 2004, 126, 11360-11369.

11 F. de Montigny, R. Macias, B. C. Noll, T. P. Fehlner, K. Costuas, J. Y. Saillard and J. F. Halet, J. Am. Chem. Soc., 2007, 129, 3392-3401.

12 A. Nafady, R. Butterick III, M. J. Calhorda, P. J. Carroll, D. Chong, W. E. Geiger and L. G. Sneddon, Organometallics, 2007, 26, 4471-4482.

13 W. Siebert, A. R. Kudinov, P. Zanello, M. Y. Antipin, V. V. Scherban, A. S. Romanov, D. V. Muratov, Z. A. Starikova and M. Corsini, Organometallics, 2009, 28, 2707-2715.

14 C. E. Webster and M. B. Hall, Coord. Chem. Rev., 2003, 238, 315-331

15 M. A. Fox, T. B. Marder and L. Wesemann, Can. J. Chem., 2009, 87, 63-71.

16 R. D. McIntosh, D. Ellis, B. T. Giles, S. A. Macgregor, G. M. Rosair and A. J. Welch, Inorg. Chim. Acta, 2006, 359, 3745-3753.

17 D. S. Perekalin, I. V. Glukhov, B. Stibr and A. R. Kudinov, Inorg. Chim. Acta, 2006, 359, 3264-3268.

18 F. A. Kiani and M. Hofmann, Organometallics, 2006, 25, 485-490.

19 N. S. Hosmane, H. M. Zhang, J. A. Maguire, Y. Wang, T. Demissie, T. J. Colacot, M. B. Ezhova, K. J. Lu, D. M. Zhu, T. G. Gray, S. C. Helfert, S. N. Hosmane, J. D. Collins, F. Baumann, W. Kaim and W. N. Lipscomb, Organometallics, 2000, 19, 497-508.

20 J. D. Lee, S. K. Kim, T. J. Kim, W. S. Han, Y. J. Lee, D. H. Yoo, M. Cheong, J. Ko and S. O. Kang, J. Am.Chem. Soc., 2008, 130, 9904-9917.

21 M. F. Hawthorne, J. I. Zink, J. M. Skelton, M. J. Bayer, C. Liu, E. Livshits, R. Baer and D. Neuhauser, Science, 2004, 303, 1849-1851.

22 M. Bühl, D. Hnyk and J. Macháček, Chem. Eur. J., 2005, 11, 4109. 
23 M. Bühl, J. Holub, D. Hnyk and J. Macháček, Organometallics, 2006, 25, 2173 2181.

24 M. Bühl, D. Hnyk and J. Macháček, Inorg. Chem., 2007, 46, 1771-1777.

25 R. Núñez, O. Tutusaus, F. Teixidor, C. Viñas, R. Sillanpää and R. Kivekäs, Chem. Eur. J., 2005, 11, 5637-5647.

26 E. J. Juárez-Pérez, C. Viñas, A. González-Campo, F. Teixidor, R. Sillanpää, R. Kivekäs and R. Núñez, Chem. Eur. J., 2008, 14, 4924-4938.

27 P. Farràs, D. Olid-Britos, C. Viñas and F. Teixidor, Eur. J. Inorg. Chem., 2011, 2525-2532

28 P. Farràs, F. Teixidor, I. Rojo, R. Kivekäs, R. Sillanpää, P. González-Cardoso and C. Viñas, J. Am. Chem. Soc., 2011, 133, 16537-16552.

29 J. Llop, C. Viñas, F. Teixidor, L. Victori, R. Kivekäs and R. Sillanpää, Organometallics, 2001, 20, 4024-4030.

30 C. Viñas, J. Llop, F. Teixidor, R. Kivekäs and R. Sillanpää, Chem. Eur. J., 2005, 11, 1933-1941.

31 D. S. Perekalin and A. R. Kudinov, Russ. Chem. Bull., 2005, 54, 1603-1605.

32 R. B. King, I. Silaghi-Dumitrescu and M. M. Uta, Eur. J. Inorg. Chem.. 2008, 39964003.

33 A. S. F. Boyd, A. Burke, D. Ellis, D. Ferrer, B. T. Giles, M. A. Laguna, R. McIntosh, S. A. Macgregor, D. L. Ormsby, G. M. Rosair and others, Pure Appl. Chem., 2003, 75, $1325-1334$.

34 G. Scott, A. McAnaw, D. McKay, A. S. F. Boyd, D. Ellis, G. M. Rosair, S. A. Macgregor, A. J. Welch, F. Laschi, F. Rossi and P. Zanello, Dalton Trans., 2010, 39, 5286-5300.

35 D. Ellis, D. McKay, S. A. Macgregor, G. M. Rosair and A. J. Welch, Angew. Chem. Int. Ed. 2010, 122, 5063-5065.

36 P. R. Schleyer, M. Bühl, U. Fleischer and W. Koch, Inorg. Chem., 1990, 29, 153155.

37 T. O. Pennanen, J. Macháček, S. Taubert, J. Vaara and D. Hnyk, Phys. Chem. Chem. Phys., 2010, 12, 7018-7025.

38 B. Barszcz, A. Graja, D. V. Ziolkovskiy, V. A. Starodub and A. V. Kravchenko, J. Mol. Struct., 2010, 976, 196-199.

39 J. A. Maguire, G. P. Ford and N. S. Hosmane, Inorg. Chem., 1988, 27, 3354-3360.

40 E. J. Juárez-Pérez, C. Viñas, F. Teixidor and R. Núñez, J. Organomet. Chem., 2009, 694, 1764-1770.

41 J. Fanfrlík, M. Lepšík, D. Horinek, Z. Havlas and P. Hobza, ChemPhysChem, 2006, 7, 1100-1105.

42 G. Chevrot, R. Schurhammer and G. Wipff, J. Phys. Chem. B, 2006, 110, 94889498.

43 E. J. Juárez-Pérez, R. Núñez, C. Viñas, R. Sillanpää and F. Teixidor, Eur. J. Inorg. Chem., 2010, 2385-2392.

44 P. Farràs, C. Viñas, R. Sillanpää, F. Teixidor and M. Rey, Dalton Trans., 2010, 39, 7684-7691.

45 P. González-Cardoso, A. I. Stoica, P. Farràs, A. Pepiol, C. Viñas and F. Teixidor, Chem. Eur. J., 2010, 16, 6660-6665. 
46 P. Matějíček, P. Cígler, K. Procházka and V. Král, Langmuir, 2006, 22, 575-581.

47 K. A. Lyssenko, D. G. Golovanov, V. I. Meshcheryakov, A. R. Kudinov and M. Y. Antipin, Russ. Chem. Bull., 2005, 54, 933-941.

48 P. Matějíček, J. Zedník, K. Ušelová, J. Pleštil, J. Fanfrlík, A. Nykänen, J.

Ruokolainen, P. Hobza and K. Procházka, Macromolecules, 2009, 42, 4829-4837.

49 J. Fanfrlík, J. Brynda, J. Řezač, P. Hobza and M. Lepšík, J. Phys. Chem. B, 2008, 112, 15094-15102.

50 J. G. Planas, C. Viñas, F. Teixidor, A. Comas-Vives, G. Ujaque, A. Lledós, M. E. Light and M. B. Hursthouse, J. Am. Chem. Soc., 2005, 127, 15976-15982.

51 O. N. Kazheva, G. G. Alexandrov, A. V. Kravchenko, I. D. Kosenko, I. A. Lobanova, I. B. Sivaev, O. A. Filippov, E. S. Shubina, V. I. Bregadze, V. A. Starodub and others, Inorg. Chem., 2011, 50, 444-450.

52 P. Cígler, M. Kožíšek, P. Řezáčova, J. Brynda, Z. Otwinowski, J. Pokorná, J. Plešek, B. Grüner, L. Dolečková-Marešová, M. Máša, J. Sedláček, J. Bodem, H. G.

Kräusslich, V. Král and J. Konvalinka, Proc. Natl. Acad. Sci.USA, 2005, 102, 15394-15399.

53 J. H. Morris, H. J. Gysling and D. Reed, Chemical Reviews, 1985, 85, 51-76.

54 R. N. Grimes, Appl. Organometallic Chem., 1996, 10, 209-225.

55 M. H. Baik and R. A. Friesner, J. Phys. Chem. A, 2002, 106, 7407-7412.

56 A. R. Kudinov, P. Zanello, R. H. Herber, D. A. Loginov, M. M. Vinogradov, A. V. Vologzhanina, Z. A. Starikova, M. Corsini, G. Giorgi and I. Nowik, Organometallics, 2010, 29, 2260-2271.

57 A. Januszko, P. Kaszynski and B. R. Grüner, Inorg. Chem., 2007, 46, 6078-6082.

58 Y. Q. Qiu, X. D. Liu, S. L. Sun, M. Fan, Z. M. Su and R. S. Wang, J. Mol. Struct.THEOCHEM, 2008, 863, 66-72.

59 N. N. Ma, Y. Q. Qiu, S. L. Sun, M. Fan and Z. M. Su, Acta Chim. Sinica, 2010, 68, 733-738.

60 A. F. Armstrong and J. F. Valliant, Dalton Trans., 2007, 4240-4251.

61 J. Fanfrlík, D. Hnyk, M. Lepšík and P. Hobza, Phys. Chem. Chem. Phys., 2007, 9, 2085-2093.

62 J. Rak, R. Kaplánek and V. Král, Bioorg. Med. Chem. Lett., 2010, 20, 1045-1048.

63 P. Řezáčová, J. Pokorná, J. Brynda, M. Kožíšek, P. Cígler, M. Lepšík, J. Fanfrlík, J. Řezač, K. G. Šašková, I. Sieglová, J. Plešek, V. Šícha, B. Grüner, H. Oberwinkler, J. Sedláček, H. G. Kräusslich, P. Hobza, V. Král and J. Konvalinka, J. Med. Chem., 2009, 52, 7132-7141.

64 P. Řezáčová, P. Cígler, P. Matějíček, M. Lepšík, J. Pokorná, B. Grüner and J. Konvalinka, in Boron Science - New Technologies and Applications., ed. N. S. Hosmane, CRC Press, New York 2011, p. 45.

65 Z. J. Lesnikowski, Collect. Czech. Chem. Commun., 2007, 72, 1646-1658.

66 R. Satapathy, B. P. Dash, J. A. Maguire and N. S. Hosmane, Collect. Czech. Chem. Commun., 2010, 75, 995-1022.

67 J. Pokorná, L. Machala, P. Řezáčová and J. Konvalinka, Viruses-Basel, 2009, 1, 1209-1239. 
68 M. Kožíšek, P. Cígler, M. Lepšík, J. Fanfrlík, P. Řezáčová, J. Brynda, J. Pokorná, J. Plešek, B. Grüner, K. G. Saskova, J. Vaclavikova, V. Kral and J. Konvalinka, J. Med. Chem., 2008, 51, 4839-4843.

69 A. K. Singh, A. Sadrzadeh and B. I. Yakobson, J. Am. Chem. Soc., 2010, 132, 14126-14129.

70 B. Grüner, J. Rais, P. Selucký and M. Lučaníková, in Boron Science- New Technologies and Applications, ed. N. S. Hosmane, CRC Press: Boca Raton, New York, 2011.

71 B. Coupez and G. Wipff, C.R. Acad. Sci. Chimie, 2004, 7, 1153-1164.

72 P. Bauduin, S. Prevost, P. Farràs, F. Teixidor, O. Diat and T. Zemb, Angew. Chem. Int. Ed., 2011, 50, 5298-5300.

73 G. Chevrot, R. Schurhammer and G. Wipff, Phys. Chem. Chem. Phys., 2007, 9, 1991-2003. 